\title{
Deforestation decreases resistance of simulated Easter Island climate to drought - Supporting Information
}

\author{
Alexander Lemburg ${ }^{1,2}$, Martin Claussen ${ }^{1,2}$, and Felix Ament ${ }^{1,2}$ \\ ${ }^{1}$ Max Planck Institute for Meteorology, Hamburg D-20146, Germany \\ ${ }^{2}$ Meteorological Institute, University of Hamburg D-20146, Germany \\ Correspondence to: Alexander Lemburg (alexander.lemburg@mpimet.mpg.de)
}

\section{Overview}

The following Supporting Information comprises a brief overview over the climate of Easter Island, a detailed description of the used numerical model and additional figures and tables. We provide further information concerning our choice of land surface parameters and synoptic case studies as well as some additional details about our methods. In addition to that, we 5 present some figures and tables supplementing our main results.

\section{Contents}

List of figures and tables

Text S1. Climate of Easter Island

Text S2. The COSMO model

Text S4. Land surface setups

Text S5. Ensemble generation 


\section{List of Figures}

S1 Model domain of coarse and fine simulation and land sea mask and topography of fine run. . . . . . . . . . . 12

S2 Precipitation for simulation CP7 with normal-sized/no/flat/enlarged island . . . . . . . . . . . . . . . 13

S3 Precipitation for simulation LSP4 with normal-sized/no/flat/enlarged island $\ldots \ldots \ldots \ldots \ldots$

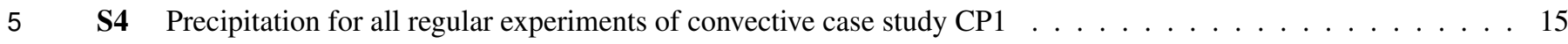

S5 Easter Island spatial averages of several quantities for convective precipitation case study CP1 $\ldots \ldots \ldots$

S6 Island spatial mean of several quantities for $\mathrm{CP} 1 \ldots \ldots \ldots \ldots \ldots \ldots \ldots \ldots$

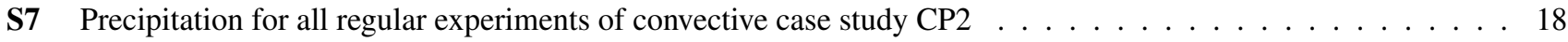

S8 Same as Fig. S7, but for convective precipitation case study CP3 (November 2002) . . . . . . . . . . . . . . 19

10 S9 Same as Fig. S7, but for convective precipitation case study CP4 (march 2002) . . . . . . . . . . . . . . . 20

S10 Area-averaged accumulated precipitation for the four large-scale precipitation experiments LSP1 - LSP4 f . 21

S11 Area-averaged accumulated precipitation for the three convective precipitation experiments CP5, CP6 and CP7 22

S12 Analysis of ERA-Interim time series for Easter Island region: frequency distribution of CAPE and wind . . . 23

S13 Climate diagram for Mataveri . . . . . . . . . . . . . . . . . . . . . . . . . . . . . . 24

15 List of Tables

S1 External (constant) land surface and vegetation parameters for the 3 land surface setups . . . . . . . . . . 25

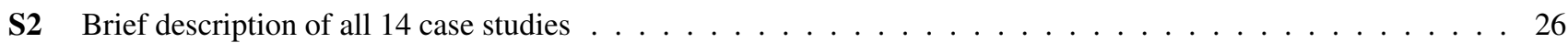

S3 Area-averaged variables for all experiments of synoptic case study CSC1 f . . . . . . . . . . . . . . . 27

S4 Relative frequency of days and their contribution to total rain amount in Easter Island region . . . . . . . . . 28

S5 Average time between two dry periods with a precipitation sum below a certain value and longest dry periods for Easter Island . . . . . . . . . . . . . . . . . . . . . . . . . . . . . . . . . . . . . . . . . . . . . . . . . . . 29 


\section{Text S1. Climate of Easter Island}

Easter Island is located within the South Pacific Subtropical Gyre which is an anticyclonic current system characterized by warm water and low nutrient concentrations (Glynn et al., 2003). The island's climate can be classified as warm and oceanic with humid autumns and winters but rather dry summers (Caviedes and Waylen, 2011). Because of its small size, Easter Island

5 is heavily influenced by the surrounding ocean which keeps the temperature amplitudes lower than the latitude would suggest. Most time of the year, from September to June, moderate trade winds from the east and south-east prevail. In the late winter months (July and August), north-westerly winds dominate (Mieth and Bork, 2004).

As depicted in figure $\mathrm{S} 13$, the monthly mean temperature ranges from $18^{\circ} \mathrm{C}$ during the coldest months July and August to $23.5^{\circ} \mathrm{C}$ in January and February resulting in an annual mean temperature of about $20.5^{\circ} \mathrm{C}$. Average daily maximum temperature is highest in February with $27.3^{\circ} \mathrm{C}$ and lowest in July and August $\left(21.2^{\circ} \mathrm{C}\right)$. Due to the all-year high water temperatures and low frequentness of calm conditions, average minimum temperatures never fall below $15^{\circ} \mathrm{C}$. The monthly-averaged relative humidity ranges from $77 \%$ to $81 \%$ throughout the year with a maximum in May and the lowest values in south-hemispheric spring and summer.

On average, the annual rainfall amounts to $1150 \mathrm{~mm}$ with windward elevated regions receiving up to $2100 \mathrm{~mm}$. The driest area is the western shore area lying in the lee of Maunga Terevaka with annual rainfall of only $600 \mathrm{~mm}$ (Stevenson et al., 2015). Overall, precipitation of above $50 \mathrm{~mm}$ is to be expected in any month in most regions. Driest period is usually composed of the south hemispheric spring and summer months whereas May shows a remarkable peak in precipitation with $150 \mathrm{~mm}$ on average. Prolonged droughts of more than two months have not been recorded. Precipitation shows a marked temporal variability. In the period from 1960 to 1999, the annual rainfall measured at Mataveri Airport ranged from 841 to $1926 \mathrm{~mm}$ (Mieth and Bork, 2004).

Because of the steady winds, evapotranspiration is high throughout the year, especially during the dry summer months. Louwagie et al. (2006) used a Penman method for estimating evapotranspiration which gives a maximum monthly value of up to $165 \mathrm{~mm}$ in January. From April until September the monthly evaporation is well below $100 \mathrm{~mm}$ with a minimum of about $55 \mathrm{~mm}$ in June. Summed over the year, their method yields about $1200 \mathrm{~mm}$. Hajek and Espinoza (1987) assume a much lower yearly evapotranspiration of $845 \mathrm{~mm}$.

Easter Island's weather conditions are mainly governed by the position and strength of the South Pacific Anticyclone (SPA), the South Pacific Convergence Zone (SPCZ) and the westerly storm tracks. During the south hemispheric summer, the SPA moves southwards and strengthens which normally leaves Easter Island slightly north of its center so that easterly winds and relative dry weather prevail. Over the winter months the SPA weakens and migrate northwards which allows the storms of the westerlies to pass the island (Saez et al., 2009). It is a matter of debate if these governing systems not only oscillate on an inter-annual and decadal scale but also significantly change on millennial time scales. Junk and Claussen (2011) simulated the climate of the last millennium with the complex earth system model MPI-ESM and found that the climate variability in the Easter Island region is rather small. 
Rapa Nui is also slightly affected by the El Nino-Southern Oscillation (ENSO) which leads to changes in predominant wind direction and sea surface temperatures in the region around the island. A study by Genz and Hunt (2003) could not find any correlation between the ENSO and Easter Island rainfall records of the last 50 years, though.

\section{Text S2. The COSMO model}

5 All simulations of this study are conducted with version 4.11 of the COSMO-CLM (Consortium for Small-Scale Modelling Model in Climate Mode) which is the climate version of the COSMO model (Rockel et al., 2008). The COSMO model, which is based on the former Lokal-Modell (LM) by Deutscher Wetterdienst (DWD), is a non-hydrostatic limited-area atmospheric prediction model (Doms and Baldauf, 2015). It has been designed for operational weather forecast as well as for various scientific research applications on small and medium mesoscale phenomena. It is based on the primitive thermo-hydrodynamical equations describing compressible flow in a moist atmosphere. The model equations are formulated in rotated geographical coordinates and a generalized terrain-following height coordinate. While a variety of physical processes have to be taken care of by parametrizations, high resolution allows to simulate processes like convection directly. As COSMO is a limited-area model it has to be driven by an external model or given boundary fields as well as initial fields. Included with the model comes the routine INT2LM which interpolates external model or reanalysis data fields to the model grid in order to provide boundary data.

\section{Governing Equations and numerics}

In COSMO the governing equations are derived from the basic conservation laws for momentum, mass and heat. These basic equations are only applicable for direct numerical simulation which will most likely never be usable for modelling of mesoscale flows. Therefore, the basic equations have to be averaged over specified time and space scales. Flow variables are separated into a mean value that describes the slowly varying resolvable part of the flow and a derivation that characterizes the fluctuating nonresolvable subgrid part of the flow. These subgrid-scale fluctuations appear trough additional terms in the form of perturbation correlations. They represent the contribution of non-resolvable phenomena to the mean flow and have to be parametrized in any case.

Because COSMO is designed to cover a wide range of spatial scales there are no scale related assumptions which would lead to the derivation of simplified (filtered) equations like the Boussinesq-approximation. After some minor simplifications, COSMO ends up with model equations that describe the evolution of the non-hydrostatic compressible mean flow capable of describing mesoscale meteorological phenomena in the atmosphere.

For numerical solution the equations are discretized by using the finite differences method on an Arakawa-C grid with Lorenz vertical staggering. There are numerous options for time stepping: default method is a second order Leapfrog HE-VI scheme (horizontally explicit, vertically implicit). It is also possible to use a three level semi implicit scheme and several Runge-Kutta schemes. Numerical smoothing is by default achieved by fourth order linear horizontal diffusion. 


\section{Model physics}

Even at high resolution, a variety of physical processes have to be taken into account by parametrization schemes. Subgrid scale turbulence is described by a 2.5 level turbulent kinetic energy closure after Mellor and Yamada (1974). Surface layer processes are simulated by means of a stability dependent drag-law formulation of momentum, heat and moisture fluxes according to similarity theory. Likewise, the latent heat flux is described with a similar expression using the transfer coefficient for turbulent exchange of moisture and the specific moisture difference between air and surface.

Radiation is calculated via a $\delta$ two stream radiation scheme after Ritter and Geleyn (1992) for short-wave and long-wave fluxes using eight spectral intervals. For grid scale clouds, cloud water condensation and evaporation is described by a saturation adjustment approach. The formation of precipitation is parametrized with the help of bulk microphysics including water vapour, cloud water, rain and snow with column equilibrium for the precipitating phases. Subgrid-scale cloudiness depends on an empirical function considering height and relative humidity.

In case of resolutions coarser than $3 \mathrm{~km}$, deep moist convection cannot be simulated directly. For such low resolution simulations a Tiedtke (1989) mass flux scheme is used to describe deep moist convection. Shallow convection, which has also to be parametrized in higher resolution runs, is described by a simplified Tiedtke scheme.

\section{Initial and boundary conditions}

COSMO can be driven by various coarse grid models (ECMWF, GME, COSMO, ERA-Interim, ECHAM/MPIOM). The external program INT2LM is used to interpolate coarse model data to the needed initial and boundary data for the high-resolution simulation. Essential atmospheric variables are $3 \mathrm{~d}$ wind components, temperature, pressure deviation from a reference pressure, specific water vapour content and specific cloud water content. The lateral boundary conditions are obtained by means of a Davies-type lateral boundary formulation based on Davies (1976). This method uses a relaxation zone at the boundaries where a lateral forcing term is added to the prognostic equations. At the top of the atmosphere, the upper-boundary condition can be realized by a rigid-lid condition or a Rayleigh damping layer.

\section{Land surface model TERRA-ML}

For this study, COSMO is used with its built-in land surface and soil model TERRA-ML (Schrodin and Heise, 2001). The submodel has the task to provide fluxes of energy and water at the surface that constitute boundary conditions for the lowermost atmospheric layer. For that, the model has to describe all important hydrological and thermal processes taking place at the surface and in different soil layers. TERRA-ML is considered a second-generation land surface model. In comparison to third generation models the depiction of vegetation is rather basic. It is characterized by plant cover fraction, leaf area index and root depth. Photosynthesis is not explicitly simulated.

Bare soil evaporation and plant evapotranspiration is calculated with the Biosphere-Atmosphere Transfer Scheme (BATS) (Dickinson et al., 1993). This is a relative simple parametrization scheme which takes a demand-supply approach as a basis where the modelled bare soil evaporation is the lesser of supply and demand quantity. For bare soil evaporation, potential 
evaporation depicts the demand quantity. Potential evaporation is described by the product of air density, the aerodynamical coefficient for turbulent moisture transfer, $10 \mathrm{~m}$ wind speed and the difference between $2 \mathrm{~m}$ air specific humidity and the saturation specific humidity at canopy temperature. The supply quantity is represented by the maximum amount of water that can diffuse upward to a dry surface which depends on soil type and soil water content. In (Dickinson et al., 1993),

5 the determination of this maximum moisture diffusion flux through the surface results from dimensional analysis, physical reasoning and tuning a two layer land-surface model with the results of a multi-layer land-surface model. The transfer of this scheme to the current multi-level soil model TERRA-ML is problematic and seems too lead to an underestimation of bare soil evaporation in drier soils (Schulz and Vogel, 2016).

Plant evapotranspiration is split up into evaporation from wet canopy and transpiration from stomata. The former is simulated

similarly to bare soil evaporation. The latter, plant transpiration, not only depends on air moisture and canopy temperature but also on the canopy surface resistance which is a function of leaf area index, turbulent moisture transfer coefficient and stomatal resistance. The latter depends on various environmental parameters including minimum and maximum stomatal resistance, solar radiation, canopy temperature and vapour pressure deficit. In TERRA-ML, the canopy layer does not have its own temperature, so the soil surface temperature is used as canopy temperature. The supply quantity is given by the water extraction of plant roots which mainly depends on soil water content (Yang and Dickinson, 1996).

TERRA-ML does not distinguish between different plant types e.g. trees and grasses. The differences between those have to be considered by different albedo, LAI, root depths and roughness lengths.

\section{Text S3. Nesting procedure and model configuration}

\section{Nesting}

20 To have a reasonable amount of island grid points, a very high resolution of $0.01^{\circ}$ is used which corresponds to a grid point spacing of approximately $1.1 \mathrm{~km}$. In the following, this will be called just $1 \mathrm{~km}$. In order to realize such high-resolution simulations, a double one-way nesting is performed. 6-hourly ECMWF (European Centre for Medium-Range Weather Forecasts) analysis fields of all needed meteorological variables, available at $0.25^{\circ}$ resolution, are interpolated to a $0.0625^{\circ}$ (approximately $7 \mathrm{~km}$ ) grid. The interpolated fields are used as initial and boundary data for the execution of a coarse model simulation. This $7 \mathrm{~km}$ simulation is carried out on a $720 \times 340$ grid which is about $5000 \times 2400 \mathrm{~km}$ as depicted in figure 1 in the main article and figure S1. There are two reasons why the domain is not square and Easter Island is not in the centre. Firstly, most of the time the large-scale flow is directed westwards because of the trade winds. Secondly, the INT2LM routine showed hard to trace errors when there were no full land points in the model domain. With the inclusion of some land points of the western tip of Chile, the errors vanished. After performing this coarse model run, hourly output data is then interpolated again to the final $1 \mathrm{~km}$ grid consisting of $300 \times 300$ grid cells in order to run the high-resolution simulations (Fig. S1b). Because Easter Island, which is represented by 156 grid points, is placed in the center of this small domain, the island and surrounding areas are not affected by lateral boundary damping effects. 


\section{Configuration of $7 \mathrm{~km}$ simulation}

The $7 \mathrm{~km}$ simulation on the $720 \times 340$ grid is run with 60 vertical levels. In the vertical, a Gal-Chen coordinate is used with a grid spacing of $20-30 \mathrm{~m}$ in the lowest $100 \mathrm{~m}$ with $20 \mathrm{~m}$ being the first layer. The model atmosphere reaches up to about $23.5 \mathrm{~km}$ where the grid spacing increases to $1200 \mathrm{~m}$. Model physics and tuning parameters are the same as in the standard operational

5 COSMO-EU configuration. For the simulation of convection the Tiedtke mass flux scheme is called every fourth time step. The vertical diffusion due to turbulent transport is modelled by an 1-D TKE based diagnostic scheme. For the model integration a third order Runge-Kutta scheme with a time step of $40 \mathrm{~s}$ is applied. A fifth-order advection scheme is used for horizontal and vertical winds, temperature and pressure and a second order Bott scheme for horizontal advection of moisture quantities. There is no nudging applied inside the model domain.

\section{Configuration of $1 \mathrm{~km}$ simulation}

The model configuration of the final $1 \mathrm{~km}$ simulation is similar to the settings used in the operational COSMO-DE model. The vertical, consisting of 90 layers this time, is described by a Gal-Chen coordinate as well, but with a grid spacing of $10-20 \mathrm{~m}$ in lowest $100 \mathrm{~m}$ with $10 \mathrm{~m}$ being the first layer. The model atmosphere reaches up to about $23.5 \mathrm{~km}$ where the grid spacing increases to $700 \mathrm{~m}$. In contrast to the coarse simulation, the $1 \mathrm{~km}$ resolution allows to simulate deep moist convection directly. Shallow non-precipitating convection can still be considered a subgrid process and is taken care of by COSMO's shallow convection scheme which is basically a simplified Tiedtke scheme. Vertical diffusion due to turbulent transport is described by an 1-D TKE based diagnostic scheme like in the coarse simulation. As opposed to the standard COSMO-DE configuration, the turbulent length scale was reduced from $150 \mathrm{~m}$ to $75 \mathrm{~m}$ because of the higher resolution. Model integration is handled by a third order Runge-Kutta scheme with a time step of $10 \mathrm{~s}$ and the same advection scheme as in the coarse run. There is no application of nudging as well.

\section{External forcing}

The land sea mask and the topographic height, shown in figure S1c, are retrieved from the web tool WebPEP (EXTPAR-3.0) (CLM-Community, 2015). For the topography the $1 \mathrm{~km}$ GLOBE (Hastings and Dunbar, 1999) data set is chosen and the land sea mask is provided by ECOCLIMAP (Champeaux et al., 2005). All other land surface parameters as leaf area index and surface roughness are set individually for each experiment (see Text S4 and Table S1).

The soil model is run with 8 layers with thicknesses of $1,2,6,18,54,162,486$ and $1458 \mathrm{~cm}$. The soil type is set to loam for all experiments. Hydrological and thermal parameters are set at their default values.

Initial soil temperature and especially soil moisture are very important for the island's heat budget. Therefore, most synoptic cases will be run with three different initial soil moisture settings. In the TERRA-ML model, soil moisture for each layer is represented by the height of a water column in meters. With the knowledge of the thickness of each layer, a volumetric soil moisture can be deduced. By dividing the volumetric soil moisture by the soil pore volume, the relative soil moisture in terms 
of soil saturation is derived. In the following, this will be the measure linked to soil moisture. The three chosen initial soil moisture values are $10 \%, 50 \%$ and $80 \%$. For some experiments only the low and high soil moisture setting is used.

The initial soil temperature is not as important for the surface energy budget as the soil moisture. There are no additional experiments with varied initial soil temperature as there are for soil moisture. To guarantee reasonable soil temperature values

5 for each synoptic case study, a simple soil temperature initialization is conducted as follows: For the 5 deepest soil layers a climatological value is calculated by solving a simple heat conduction equation assuming an appropriate sinusoidal annual surface temperature variation. The surface temperature is calculated by the model by solving the surface energy budget. The temperatures of the remaining two surface-near layers are then fit exponentially to the climatological values of the deeper layers.

\section{Text S4. Land surface setups}

Table S1 lists all land surface parameters for these three land surface setups. The chosen dry soil albedo of 0.14 is on the low side of the typical soil albedo spectrum because the soils of Easter Island are rather dark. The LAI of the tree-covered island is set very high on purpose to represent the upper limit that can be expected from a very dense forest of tropical palm trees. The grass island, a portrayal of today's island is only covered by $70 \%$ grass and is also given a low LAI of 1 . This reflects the poor and short grass that covers most of the island. Root depths are set exceptionally low to account for the poor water availability of the porous soils.

\section{Text S5. Ensemble generation}

Precipitation is a problematic quantity due to its complex formation mechanism, high spatial inhomogeneity and strong dependency on the initial model state. Therefore, all precipitation-focused case studies are executed as a mini ensemble consisting of five members. These ensemble runs are generated with the domain shifting method where the model domain is shifted by some grid points to receive slightly changed boundary conditions which allow another realization to evolve. So member one has its domain shifted by 6 grid points to the north, member two has its domain shifted by 6 grid points to the west and so on and so forth.

\section{Text S6. Sensitivity Experiments}

Before our main experiments we want to test whether the small island even affects precipitation. For this, three distinct precipitation (undisturbed convection, frontal convection, large-scale precipitation) cases are simulated with a regular-sized island, without an island, with a flat island (topographic height set to $1 \mathrm{~m}$ ) and with an enlarged island (by factor 4 and 10). All of these experiments are performed with the bare soil setting with an initial soil moisture of $80 \%$. The exact procedure for the enlarging of Easter Island is as follows: The tool WebPEP, that provides external data as land sea mask or topographic height, is used with a resolution of $0.5 \mathrm{~km}$ instead of $1 \mathrm{~km}$. Then, the longitude and latitude info of the new model domain file is replaced by 
the old grid information. This gives the same model domain as before but with an island that is approximately 4 times as large. The same procedure is also performed with $0.3 \mathrm{~km}$ which provides a model domain with an island approximately 10 times as big as Easter Island. 


\section{References}

Caviedes, C. N. and Waylen, P. R.: Rapa Nui: A climatically constrained island?, Journal and Article number: RNJ2011, 1, $01,2011$.

Champeaux, J., Masson, V., and Chauvin, F.: ECOCLIMAP: a global database of land surface parameters at 1 km resolution, Meteorological Applications, 12, 29-32, 2005.

5 CLM-Community: WebPep (EXTPAR-3.0), Website of the Climate Limited-area Modelling-Community, http://www.clm-community.eu/ index.php?menuid=221, online; accessed multiple times between 02-2015 and 12-2015, 2015.

Davies, H.: A laterul boundary formulation for multi-level prediction models, Quarterly Journal of the Royal Meteorological Society, 102, 405-418, 1976.

Dickinson, R. E., Kennedy, P., and Henderson-Sellers, A.: Biosphere-atmosphere transfer scheme (BATS) version 1e as coupled to the NCAR community climate model, National Center for Atmospheric Research, Climate and Global Dynamics Division, 1993.

Doms, G. and Baldauf, M.: A Description of the Nonhydrostatic Regional COSMO-Model Part I: Dynamics and Numerics, 2015.

Genz, J. and Hunt, T. L.: El Nino/southern oscillation and Rapa Nui prehistory, Rapa Nui Journal, 17, 7-14, 2003.

Glynn, P. W., Wellington, G., Wieters, E., and Navarrete, S. A.: Reef-building coral communities of Easter Island (Rapa Nui), Chile, Latin American Coral Reefs. Elsevier Science, Amsterdam, pp. 473-494, 2003.

Hajek, E. and Espinoza, G.: Meteorología, climatología y bioclimatología de las islas oceánicas chilenas, Islas oceánicas chilenas: Conocimiento científico y necesidades de investigación, pp. 55-83, 1987.

Hastings, D. A. and Dunbar, P. K.: Global land one-kilometer base elevation (GLOBE) digital elevation model, documentation, Key to Geophysical Records Documentation (KGRD), 34, 1999.

Junk, C. and Claussen, M.: Simulated climate variability in the region of Rapa Nui during the last millennium, Climate of the Past, 7 , 579-586, 2011.

Louwagie, G., Stevenson, C. M., and Langohr, R.: The impact of moderate to marginal land suitability on prehistoric agricultural production and models of adaptive strategies for Easter Island (Rapa Nui, Chile), Journal of Anthropological Archaeology, 25, $290-317,2006$.

Mellor, G. L. and Yamada, T.: A hierarchy of turbulence closure models for planetary boundary layers, Journal of the Atmospheric Sciences, 31, 1791-1806, 1974.

Mieth, A. and Bork, H.-R.: The Dynamics of Soil, Landscape and Culture on Easter Island (Chile), in: Breaking the sod: Humankind, history, and soil, edited by McNeill, J. R. and Winiwarter, V., chap. 10, pp. 273-321, American Association for the Advancement of Science, Oxford, 2004.

Ritter, B. and Geleyn, J.-F.: A comprehensive radiation scheme for numerical weather prediction models with potential applications in climate simulations, Monthly Weather Review, 120, 303-325, 1992.

30 Rockel, B., Will, A., and Hense, A.: The regional climate model COSMO-CLM (CCLM), Meteorologische Zeitschrift, 17, 347-348, 2008.

Saez, A., Valero-Garces, B. L., Giralt, S., Moreno, A., Bao, R., Pueyo, J. J., Hernandez, A., and Casas, D.: Glacial to Holocene climate changes in the SE Pacific. The Raraku lake sedimentary record (Easter Island, 27 S), Quaternary Science Reviews, 28, 2743-2759, 2009.

Schrodin, R. and Heise, E.: The multi-layer version of the soil model TERRA_LM. Consortium for Small-Scale Modelling (COSMO), Tech. rep., Technical Report 2, 17 pp. http://www. cosmo-model. org, 2001.

Schulz, J.-P. and Vogel,G. : A new parameterisation of bare soil evaporation for the land surface scheme TERRA of the COSMO atmospheric model, ftp://ftp-anon.dwd.de/pub/DWD/Forschung_und_Entwicklung/CUS2016_presentations_PDF/02_Soil_Vegetation_ and_Ocean/01_Schulz_Vogel/userseminar2016_jps.pdf, online presentation, 2016; accessed 23-June-2016, 2016. 
Stevenson, C. M., Puleston, C. O., Vitousek, P. M., Chadwick, O. A., Haoa, S., and Ladefoged, T. N.: Variation in Rapa Nui (Easter Island) land use indicates production and population peaks prior to European contact, Proceedings of the National Academy of Sciences, 112 , 1025-1030, 2015.

Tiedtke, M.: A comprehensive mass flux scheme for cumulus parameterization in large-scale models, Monthly Weather Review, 117, 1779_ 5 1800, 1989.

Universidad de Chile: Información climatológica de estaciones chilenas: Chile Norte, http://www.atmosfera.cl/HTML/climatologia/DATOS/ CHILENORTE.HTM, online; accessed 15-August-2015, 2011.

World Meteorological Organization: World Meteorological Organization Standard Normals, http://data.un.org/Explorer.aspx?d=CLINO, online; accessed 12-August-2015, 2010.

10 Yang, Z.-L. and Dickinson, R. E.: Description of the Biosphere-Atmosphere Transfer Scheme (BATS) for the Soil Moisture Workshop and evaluation of its performance, Global and Planetary Change, 13, 117-134, 1996. 

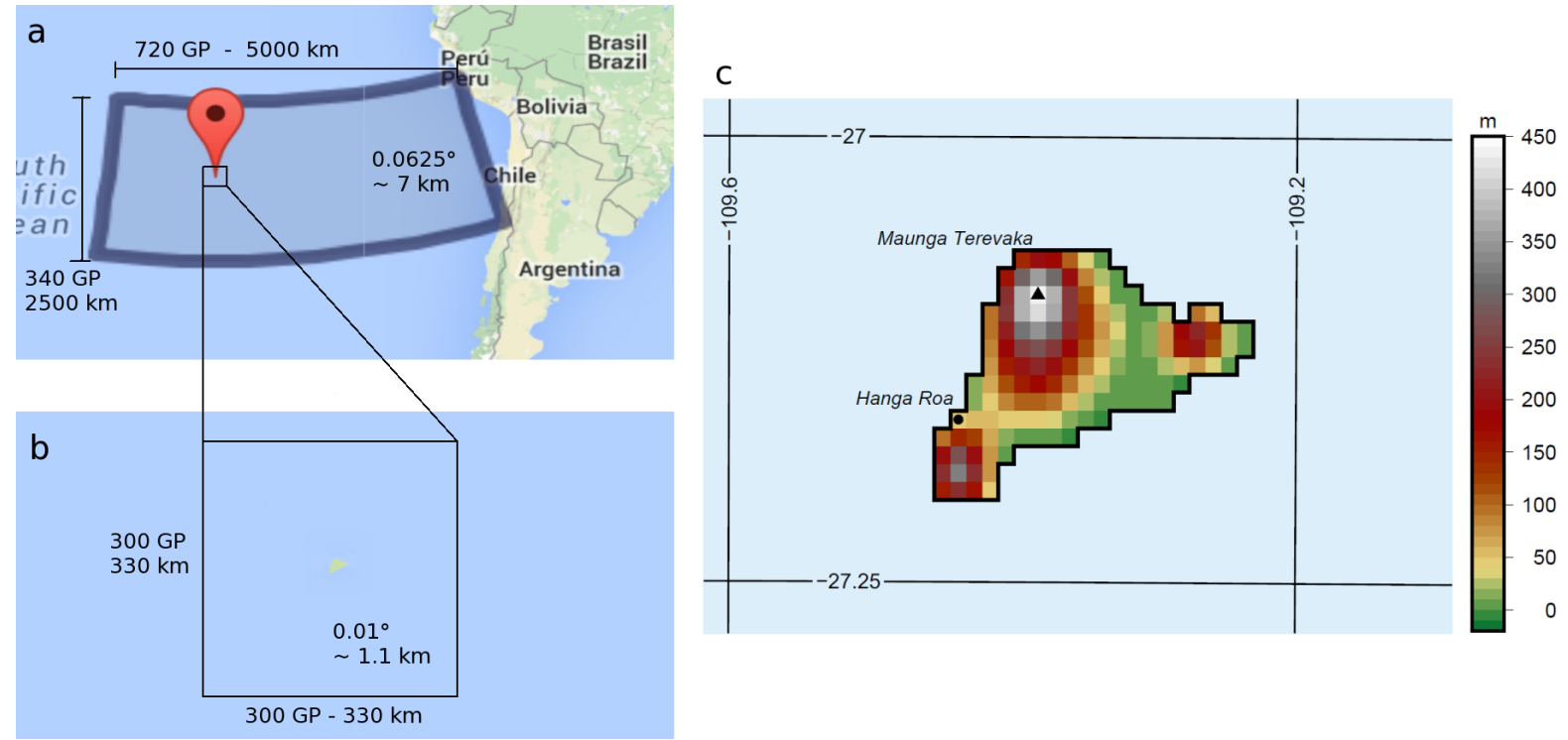

Figure S1. Model domain of coarse and fine simulation and land sea mask and topography of fine run. a) Dimension of the model domain of the preceding $7 \mathrm{~km}$ simulation which is driven by ECMWF analysis data at $0.25^{\circ}$ resolution. b) Dimension of the final high resolution $1 \mathrm{~km}$ simulation which is driven by the output of the $7 \mathrm{~km}$ simulation. c) Land sea mask and topography in our high resolution simulations. 
a

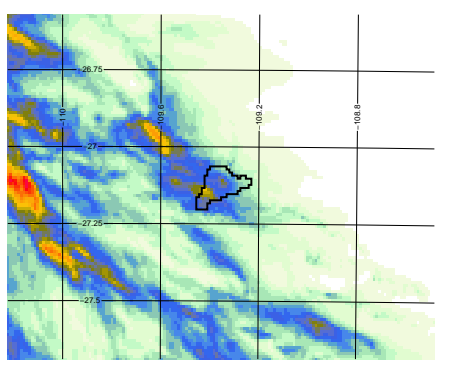

d

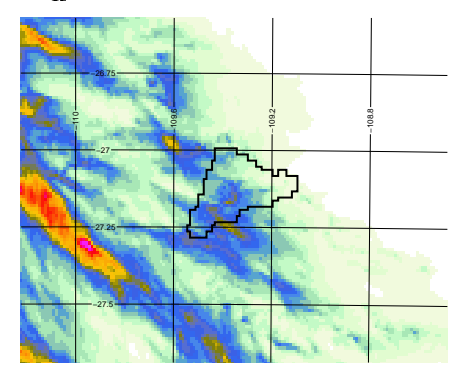

b

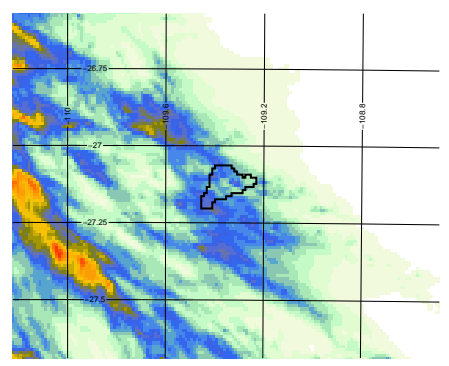

e

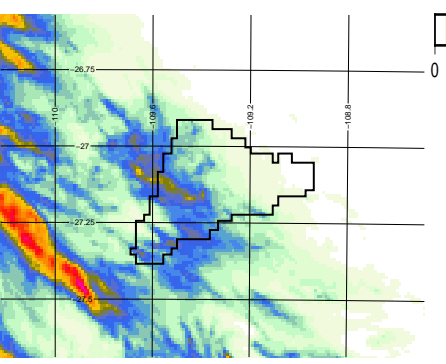

c
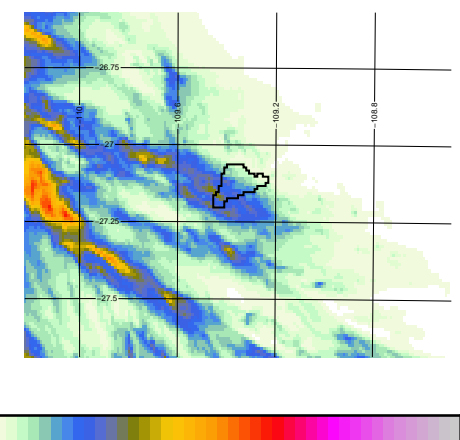

$\begin{array}{llllllll}50 & 100 & 150 & 200 & 250 & 300 & 350 & 400\end{array}$

area-averaged precipitation

maximum precipitation

a) $71.99 \pm \mathbf{1 0 . 0 6} \quad \mathbf{1 5 6 . 8 9} \pm \mathbf{2 0 . 9 5}$

b) $54.49 \pm 14.5 \quad 100.20 \pm 21.54$

c) $61.56 \pm 3.31 \quad 127.85 \pm 9.91 \checkmark$

d) $60.91 \pm \mathbf{5 . 6 0} \quad \mathbf{1 8 9 . 8 9} \pm \mathbf{3 7 . 4 9}$

e) $45.67 \pm 3.72 \checkmark \quad \mathbf{1 7 2 . 7 4} \pm \mathbf{2 0 . 0 0}$

Figure S2. Precipitation sensitivity experiment for the more synoptically disturbed convective precipitation simulation CP7 with normalsized/no/flat/enlarged island. 96-hour precipitation sum [mm] for simulation CP7: a) normal-sized island, b) no island, c) flat island, d) island enlarged by factor 4 , e) island enlarged by factor 10. For each simulation ensemble member No. 1 is depicted. Mean and maximum values at the bottom right corner represent the 5-member ensemble mean of the island's spatial mean and island maximum. Checks indicate statistical significance of difference to normal-sized island simulation (t-test at $5 \%$ level) 
a

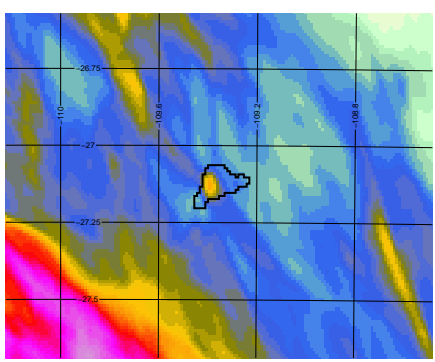

d

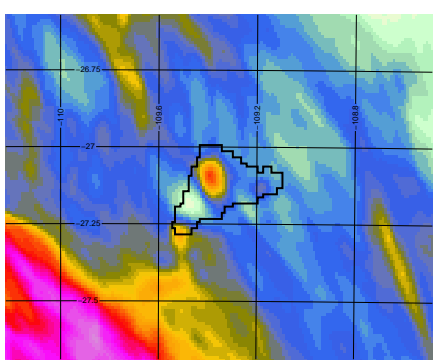

b

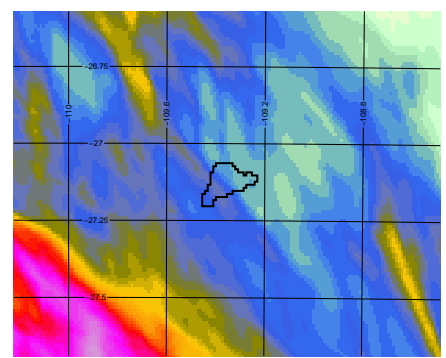

e

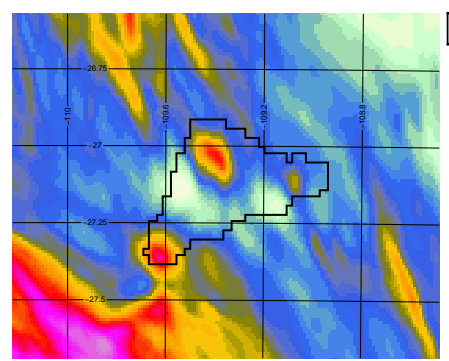

c
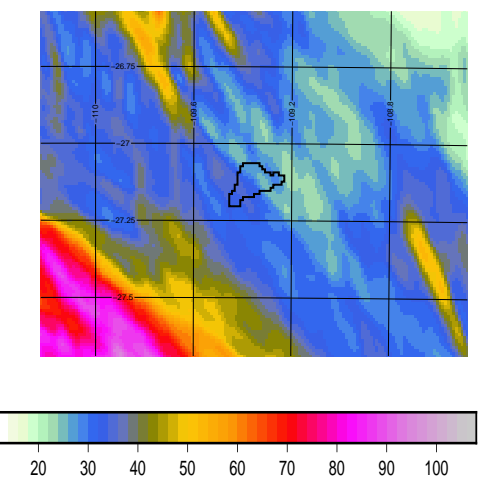

area-averaged maximum precipitation precipitation

a) $35.17 \pm 1.47 \quad 52.68 \pm \mathbf{4 . 8 7}$

b) $29.84 \pm 1.54 \checkmark \quad 36.87 \pm 1.63 \checkmark$

c) $30.10 \pm 1.44 \checkmark \quad 36.91 \pm 1.70 \checkmark$

d) $33.93 \pm 0.59 \quad 67.57 \pm 3.18$

e) $33.37 \pm 0.36 \checkmark \quad 76.42 \pm 3.84 \checkmark$

Figure S3. Precipitation sensitivity experiment for the large-scale precipitation simulation LSP4 with normal-sized/no/flat/enlarged island. 96-hour precipitation sum [mm] for simulation LSP4: a) normal-sized island, b) no island, c) flat island, d) island enlarged by factor 4, e) island enlarged by factor 10. For each simulation ensemble member No. 1 is depicted. Mean and maximum values at the bottom right corner represent the 5-member ensemble mean of the island's spatial mean and island maximum. Checks indicate statistical significance of difference to normal-sized island simulation (t-test at $5 \%$ level) 

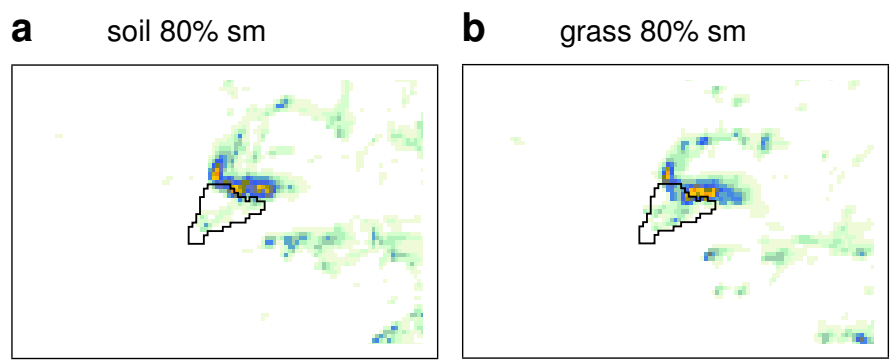

C trees $80 \% \mathrm{sm}$
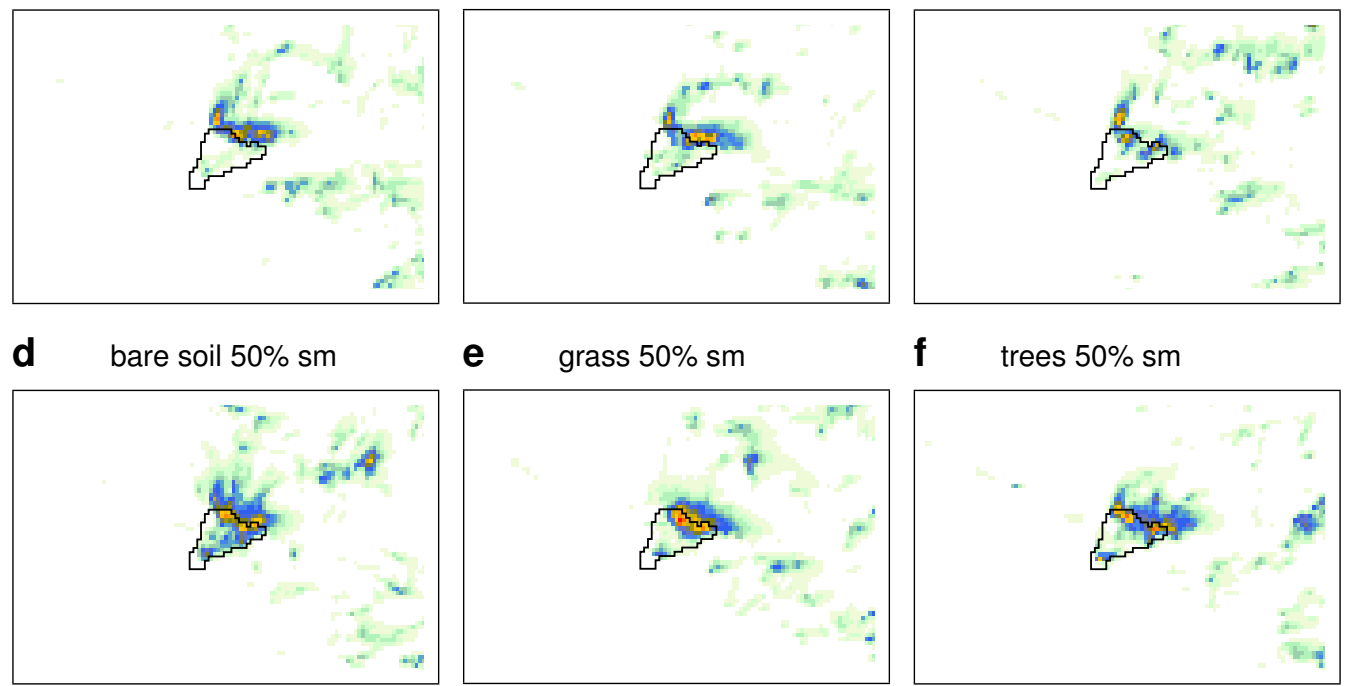

f trees $50 \% \mathrm{sm}$
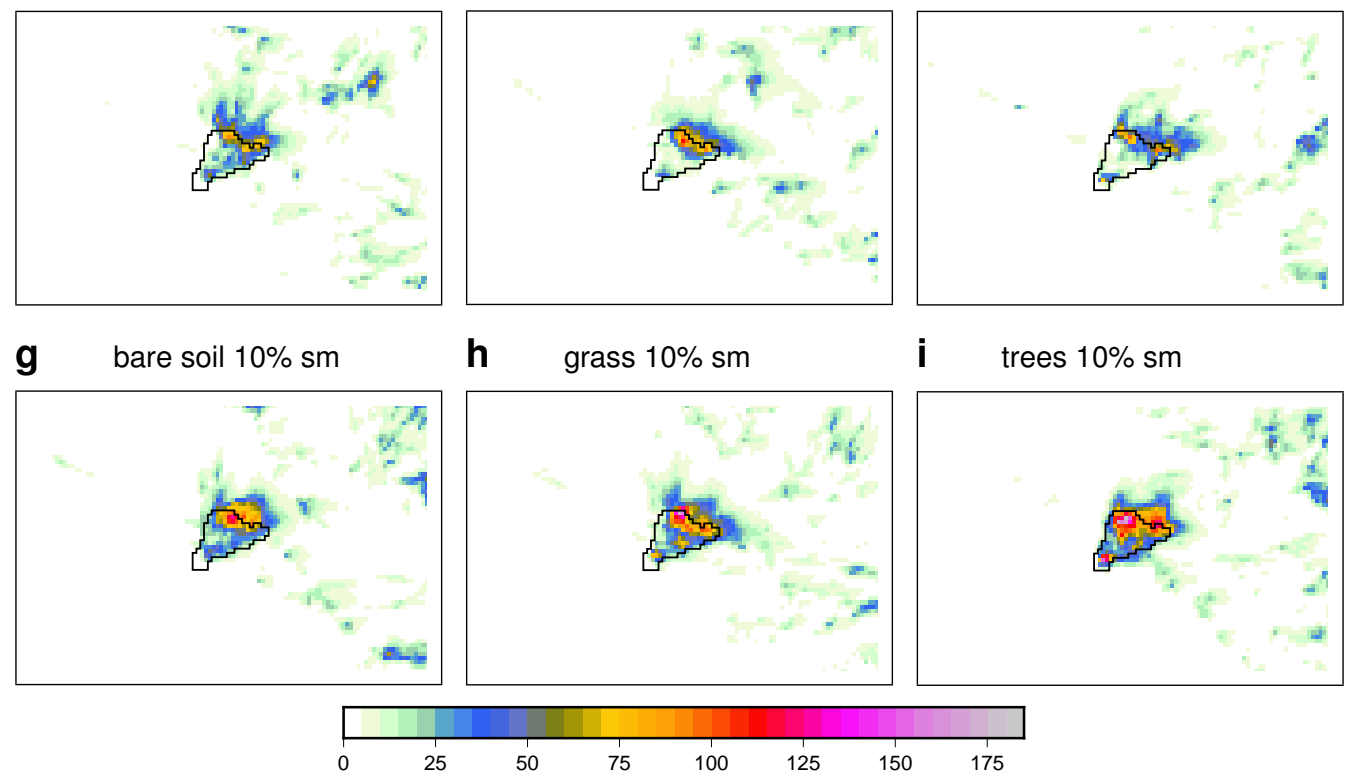

Figure S4. 96-hour precipitation sum [mm] for all main experiments of convective case study CP1. Shown are the results from ensemble member 1 for each experiment. These are the results from the particular case study shown in figure 1 in the main article with added results for $50 \%$ initial soil moisture. 
a

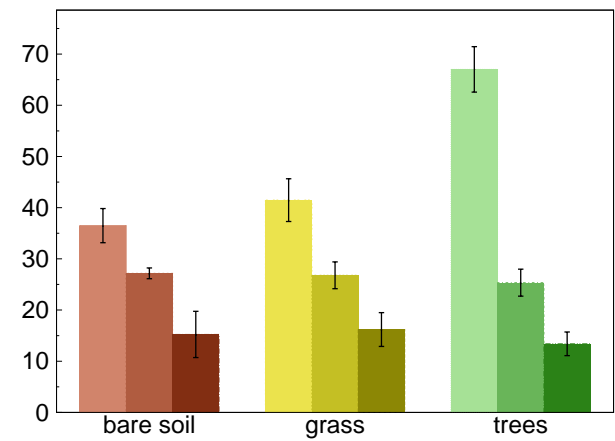

C Sensible heat flux $\left[\mathrm{W} / \mathrm{m}^{2}\right](9 \mathrm{am}-12 \mathrm{am})$

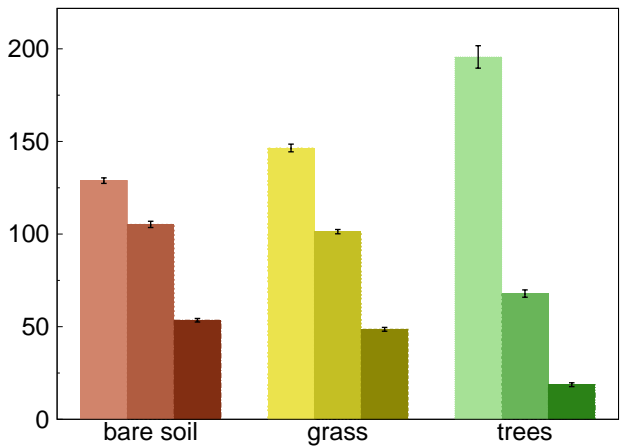

b Precipitation sum maximum [mm]

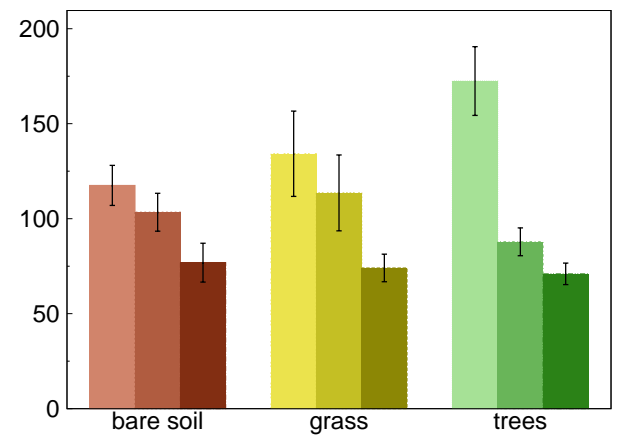

d Latent heat flux $\left[\mathrm{W} / \mathrm{m}^{2}\right](9 \mathrm{am}-12 \mathrm{am})$

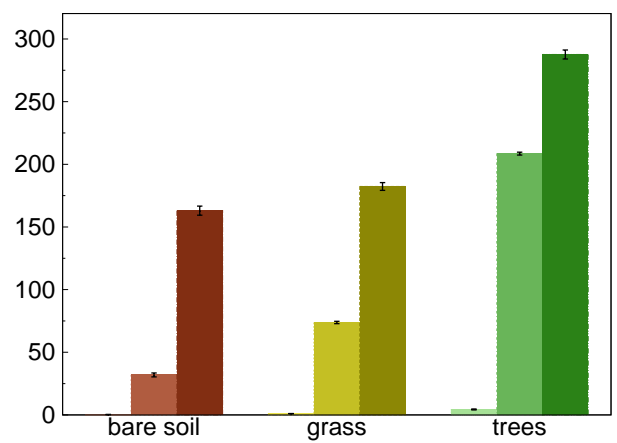

Figure S5. 4-day forenoon (9am - 12am) and afternoon (12am - 5pm) mean values for Easter Island spatial averages of several quantities for convective precipitation case study CP1. These are further results from the particular case study shown in figure 1 in the main article. Precipitation sum maximum (b) is Easter Island's spatial maximum of accumulated rainfall. The lightest bars represent the low initial soil moisture, the darkest bars the high soil moisture case. Error bars represent ensemble standard deviation. 
a

Boundary layer depth [m] (9am - 12am)

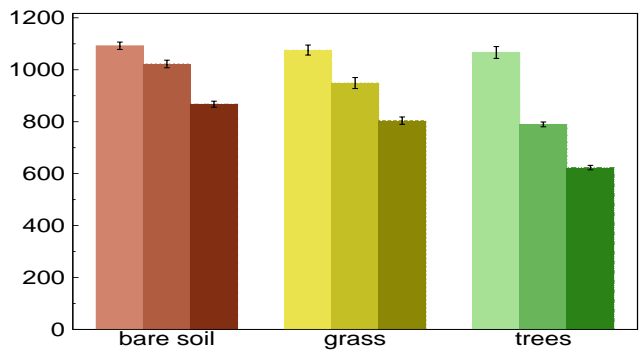

C

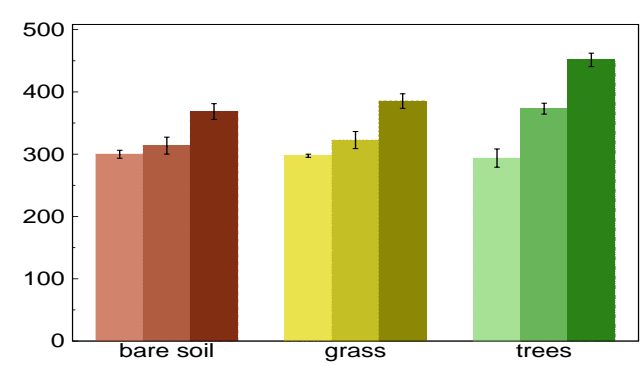

e

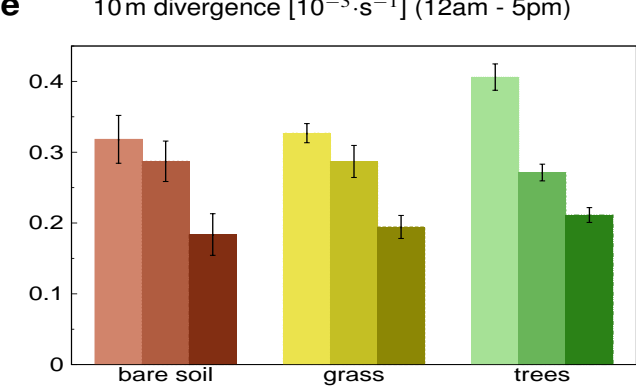

g

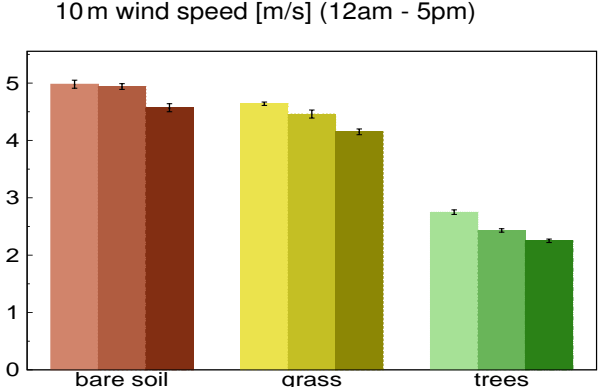

b Cloud base height [m] (9am - 12am)

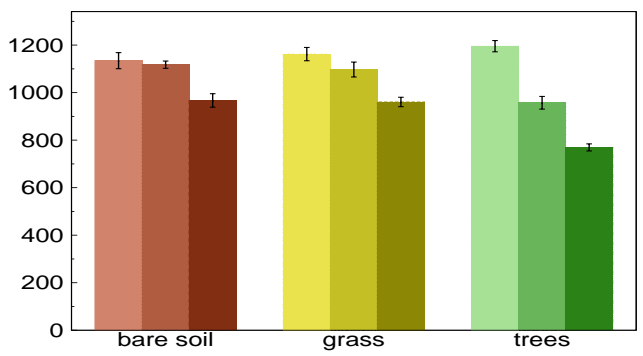

d

Maximum updraft speed $[\mathrm{m} / \mathrm{s}]$

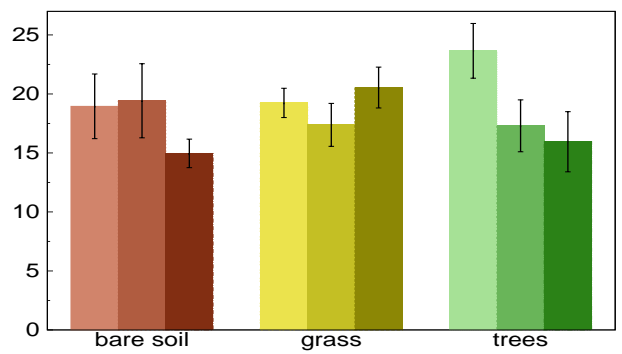

f

Moist. flux conv. $\left[10^{-3} \cdot \mathrm{g} /(\mathrm{kg} \cdot \mathrm{s})\right](12 \mathrm{am}-5 \mathrm{pm})$

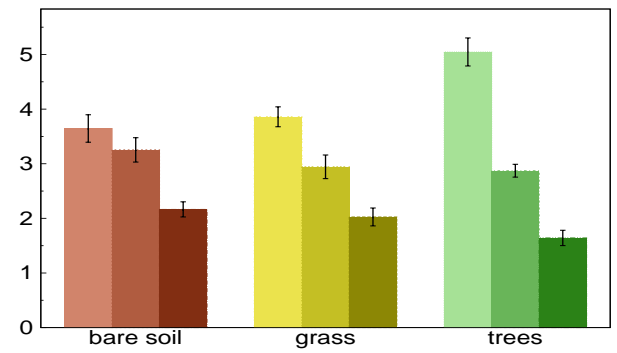

h

$10 \mathrm{~m}$ wind gust speed $[\mathrm{m} / \mathrm{s}](12 \mathrm{am}-5 \mathrm{pm})$

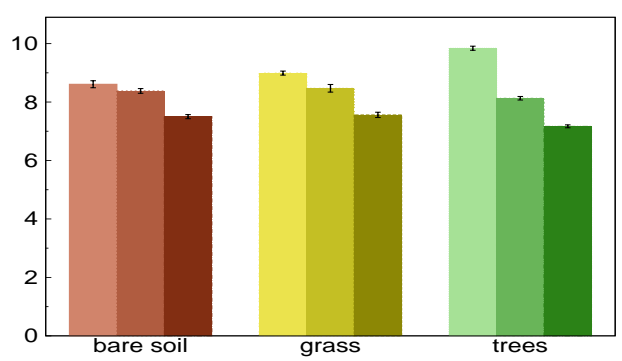

Figure S6. 4-day forenoon (9am - 12am) and afternoon (12am - 5pm) mean values for Easter Island spatial averages of several quantities for convective precipitation case study CP1. These are further results from the particular case study shown in figure 1 in the main article. The maximum updraft speed is the spatial and temporal maximum. The depicted moisture flux convergence is the average boundary layer moisture flux convergence between surface and roughly $700 \mathrm{~m}$ (as in Fig. 1c of the main article). The lightest bars represent the low initial soil moisture, the darkest bars the high soil moisture case. Error bars represent ensemble standard deviation. 


\section{b grass $80 \% \mathrm{sm}$}

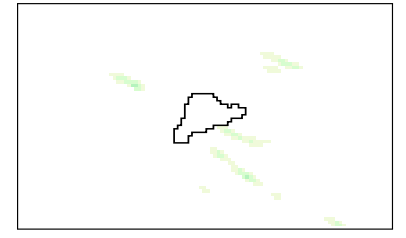

d bare soil $50 \% \mathrm{sm}$

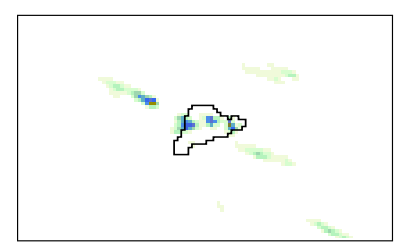

g bare soil $10 \% \mathrm{sm}$
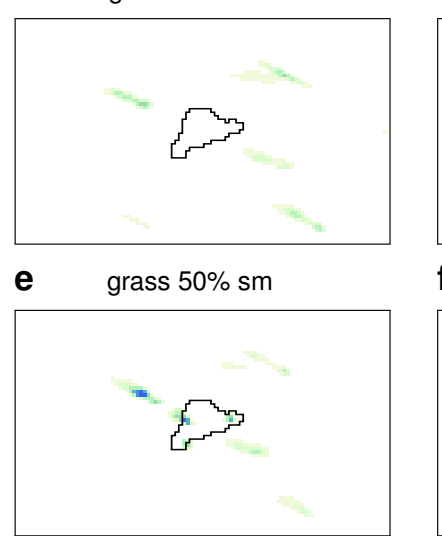

h grass $10 \% \mathrm{sm}$
C trees $80 \% \mathrm{sm}$

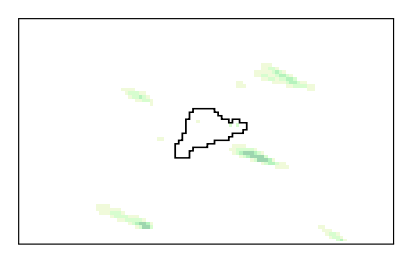

f trees $50 \% \mathrm{sm}$

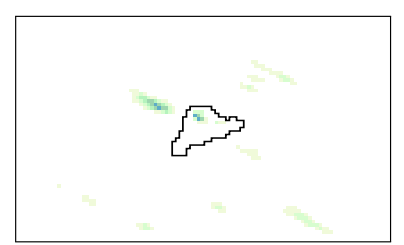

i trees $10 \% \mathrm{sm}$

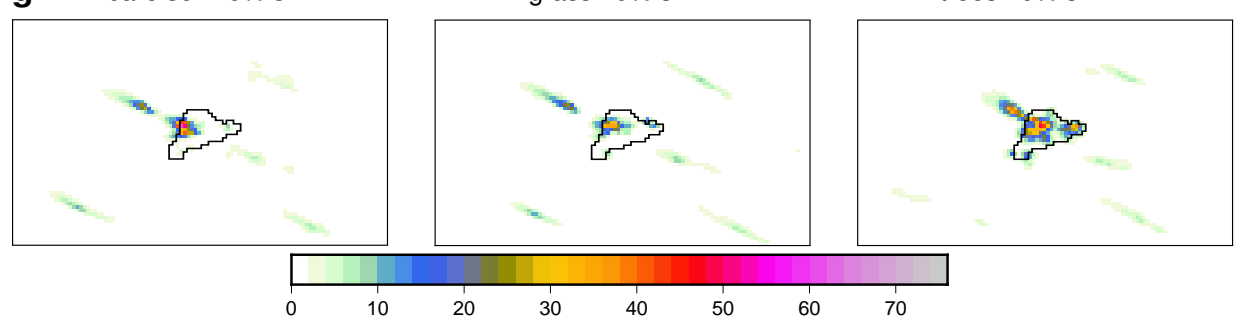

j Precipitation sum [mm]

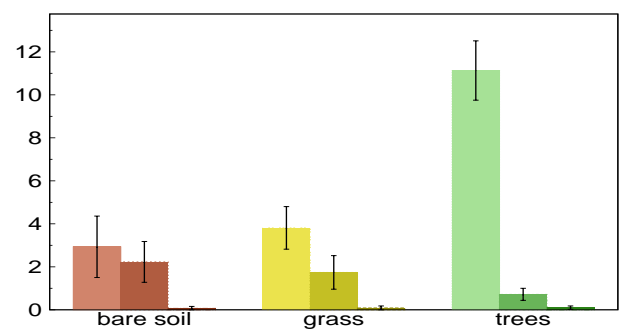

k Precipitation sum maximum [mm]

I Sensible heat flux $\left[\mathrm{W} / \mathrm{m}^{2}\right](9 a m-12 a m)$
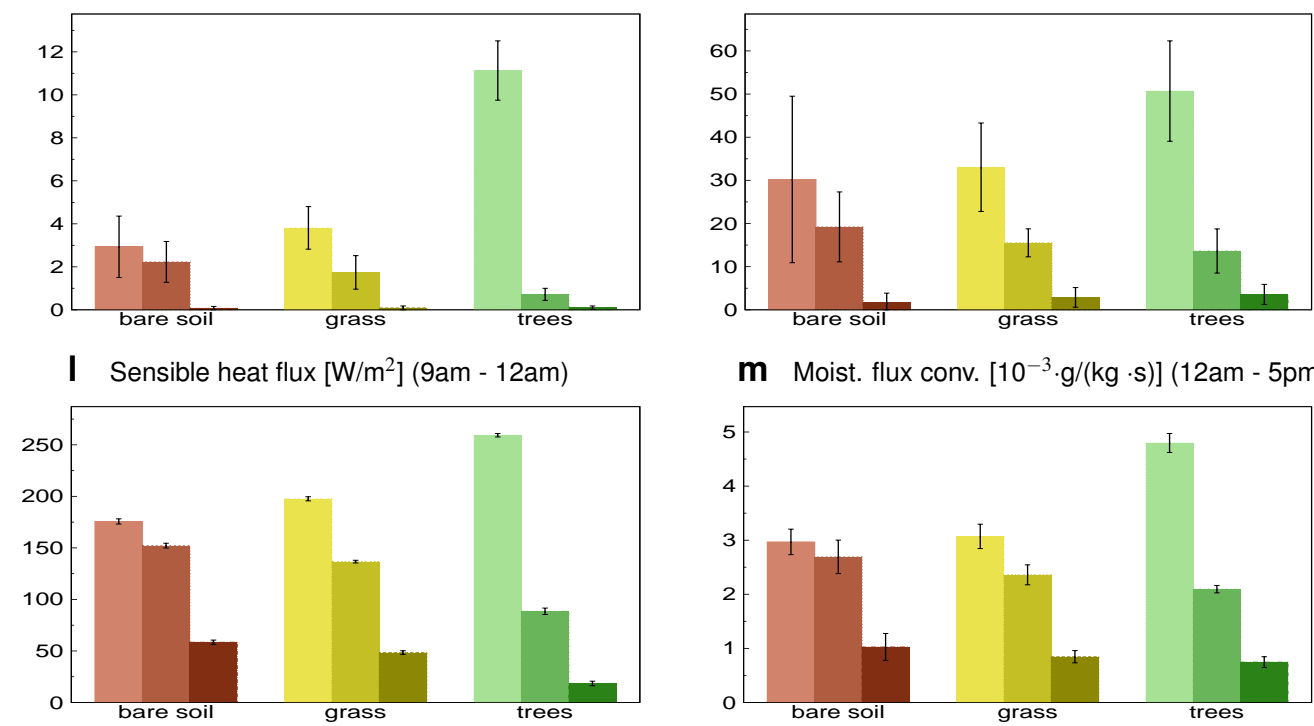

m Moist. flux conv. $\left[10^{-3} \cdot \mathrm{g} /(\mathrm{kg} \cdot \mathrm{s})\right](12 \mathrm{am}-5 \mathrm{pm})$

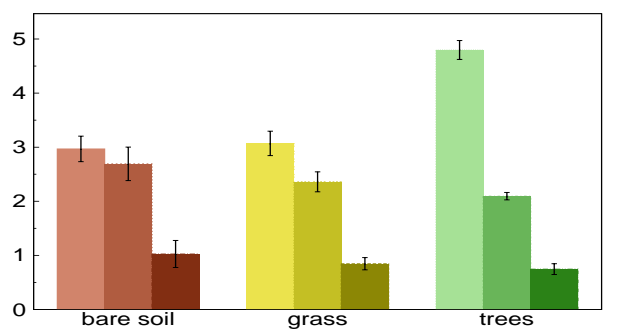

Figure S7. 96-hour precipitation sum and average forenoon sensible heat flux and afternoon moisture flux convergence for all main experiments of convective precipitation case study CP2 (January 2006). a-i) 96-hour accumulated precipitation sum of ensemble member 1 for all land surfaces and initial soil moisture settings. j-m) Comparison between accumulated area-averaged precipitation (a), accumulated precipitation field maximum (b), average forenoon (0900LT-1200LT) sensible heat flux (c) and average afternoon (1200LT-1700LT) boundary layer moisture flux convergence (c). The light bars represent the low initial soil moisture, the darker bars the high soil moisture case. 
a bare soil $80 \% \mathrm{sm}$

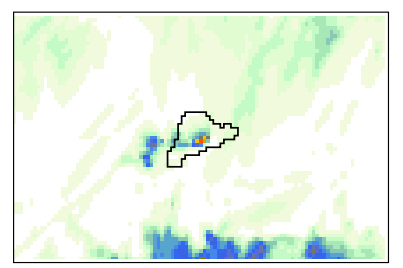

d bare soil $50 \% \mathrm{sm}$

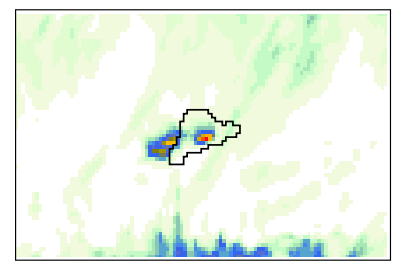

g bare soil $10 \% \mathrm{sm}$

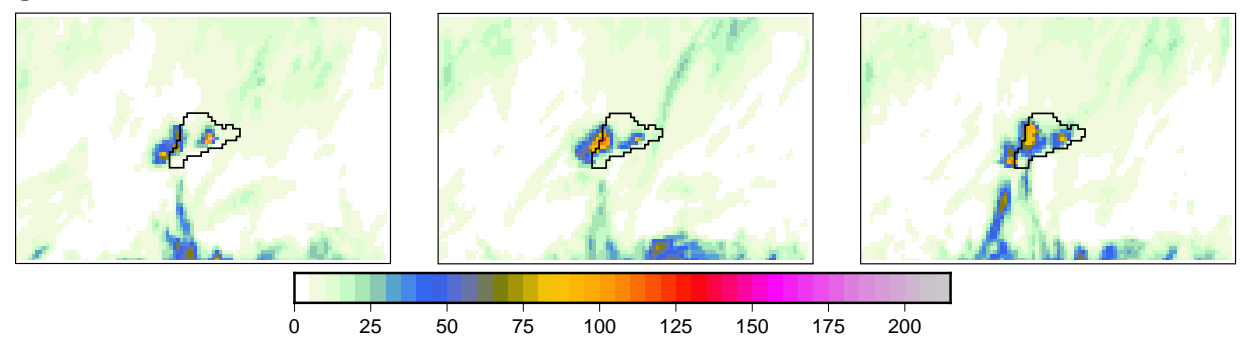

j Precipitation sum [mm]

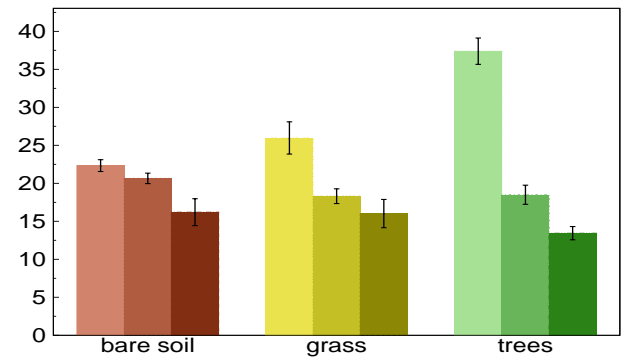

I Sensible heat flux [W/m²] (9am - 12am)

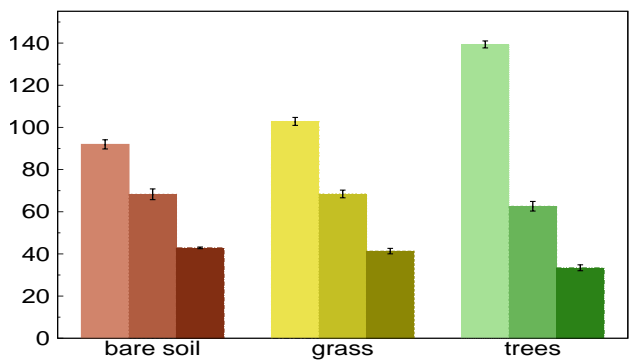

K Precipitation sum maximum [mm]

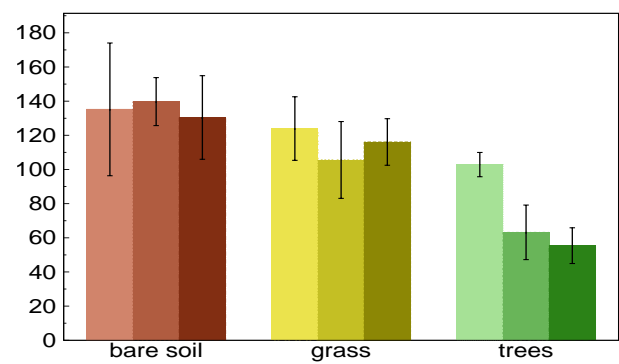

m Moist. flux conv. $\left[10^{-3} \cdot \mathrm{g} /(\mathrm{kg} \cdot \mathrm{s})\right](12 \mathrm{am}-5 \mathrm{pm})$

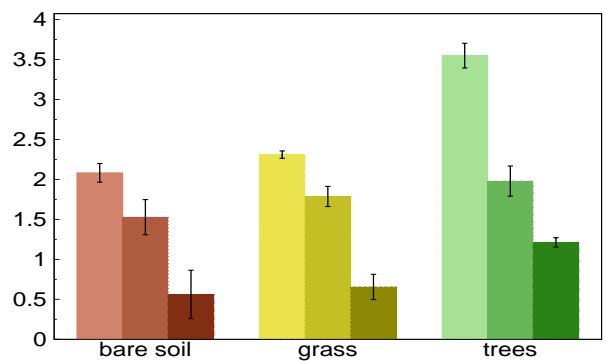

Figure S8. Same as Fig. S7, but for convective precipitation case study CP3 (November 2002). 

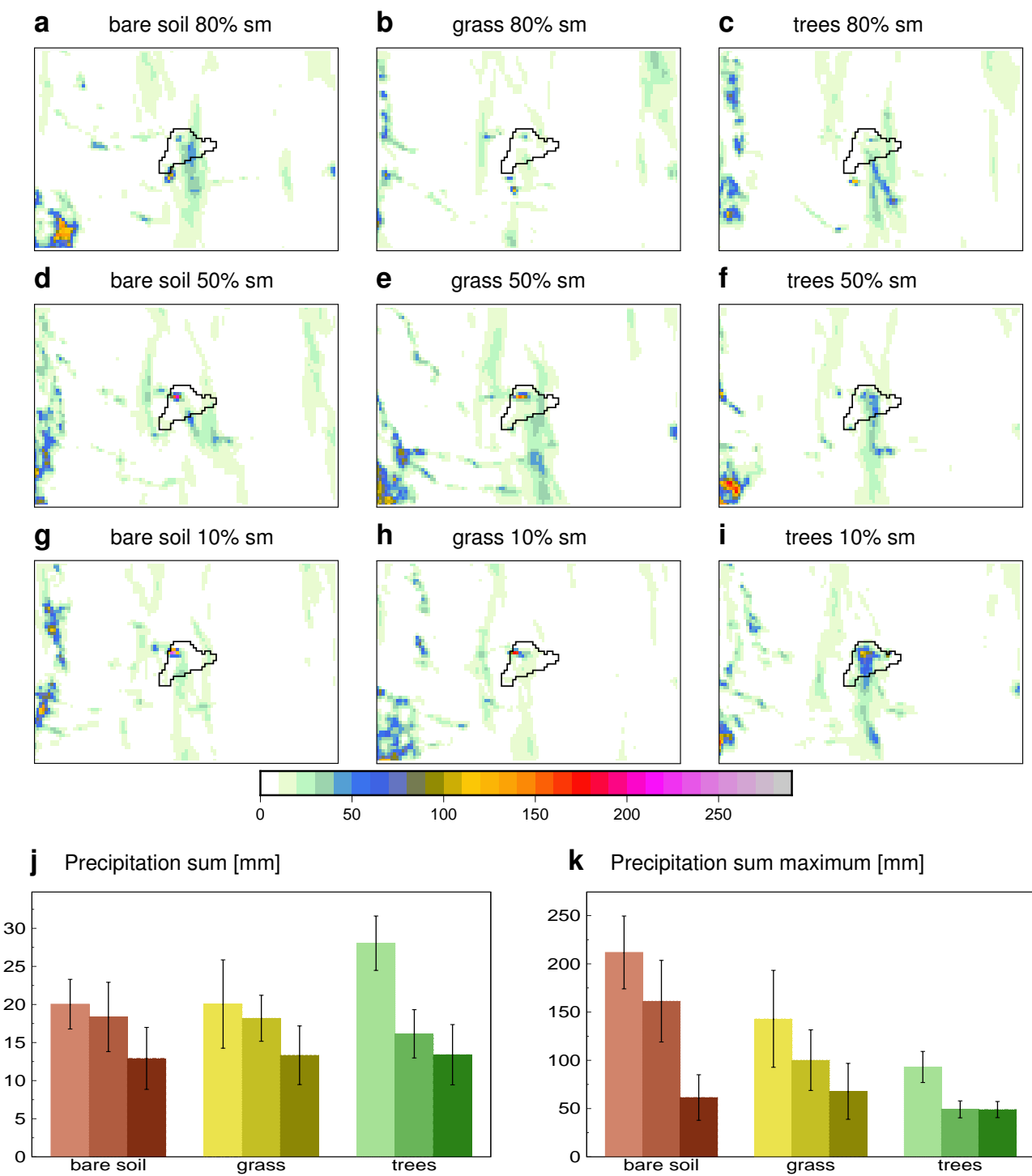

K Precipitation sum maximum [mm]

I Sensible heat flux $\left[\mathrm{W} / \mathrm{m}^{2}\right](9 a m-12 a m)$
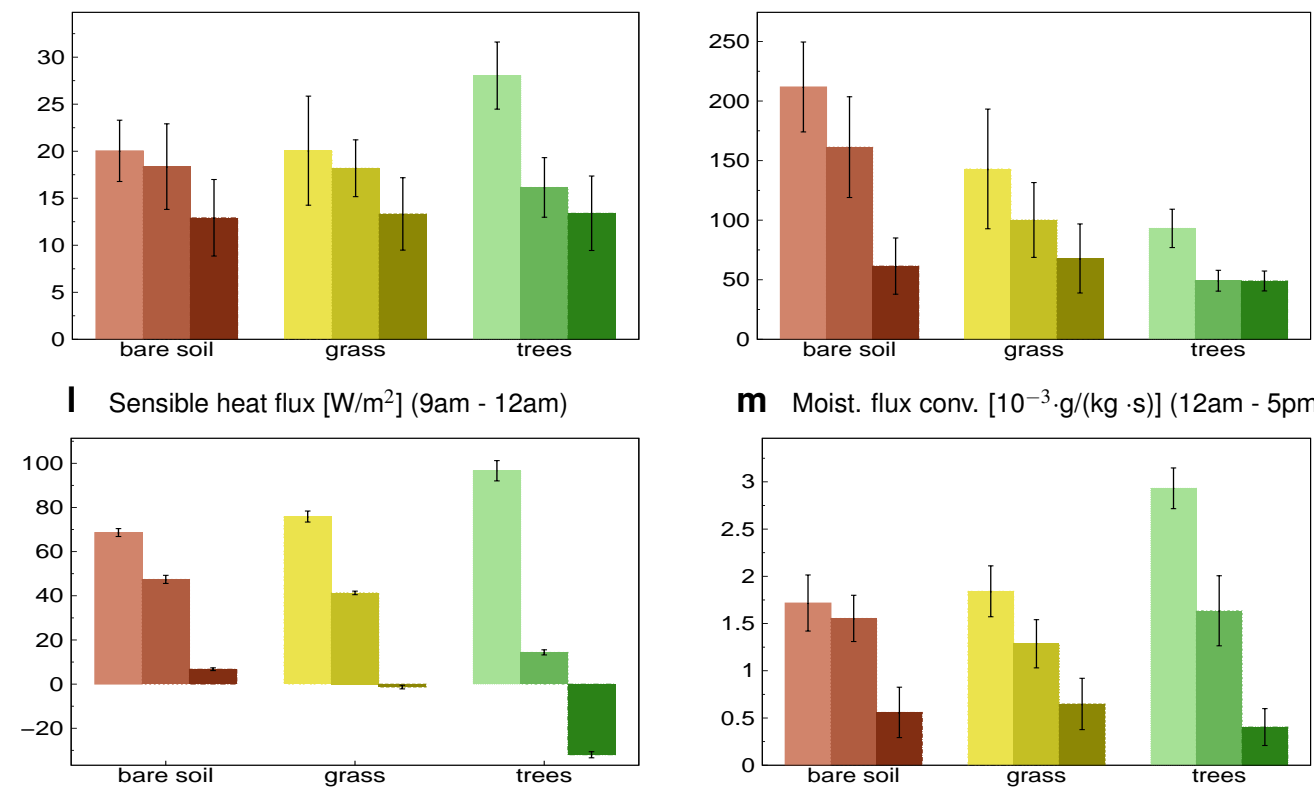

m Moist. flux conv. $\left[10^{-3} \cdot \mathrm{g} /(\mathrm{kg} \cdot \mathrm{s})\right](12 \mathrm{am}-5 \mathrm{pm})$

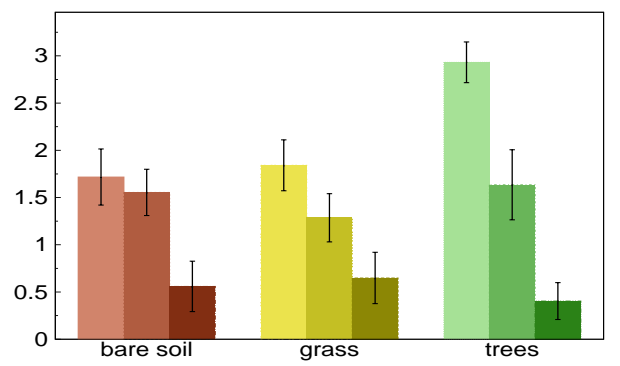

Figure S9. Same as Fig. S7, but for convective precipitation case study CP4 (march 2002). 
a $\quad$ LSP1 (July 25th -28th, 2005)

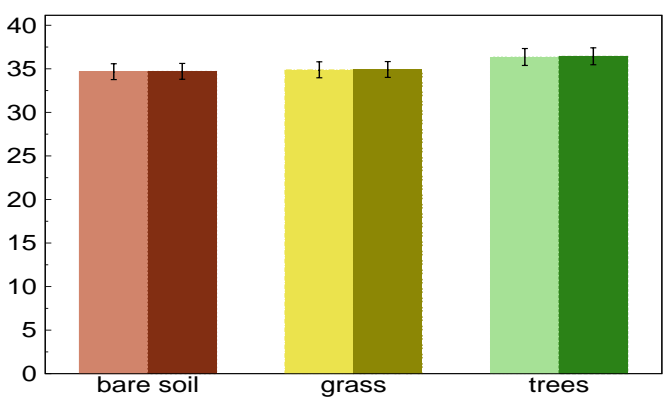

C LSP3 (July 26th-29th, 2003)

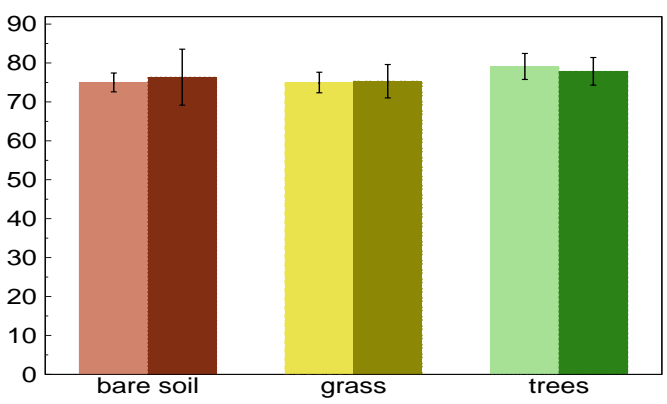

b LSP2 (September 27th-30th, 2009)

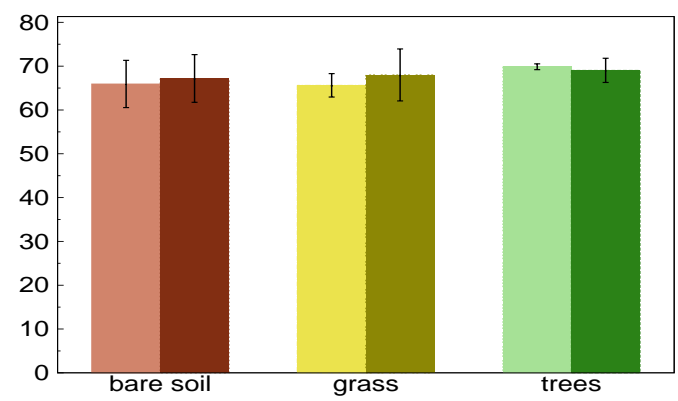

d LSP4 (November 2nd-5th, 2009)

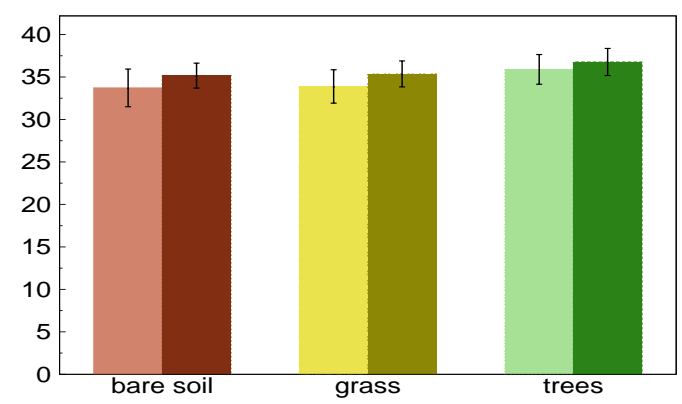

Figure S10. Area-averaged accumulated precipitation for the four large-scale precipitation [mm] experiments LSP1 - LSP4. The light bars represent the low initial soil moisture, the darker bars the high soil moisture case. 
a $\quad$ CP5 (February 17th -20th, 2004)

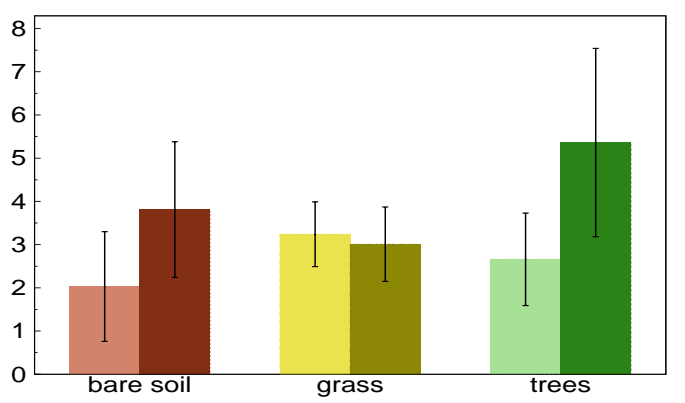

b $\quad$ CP6 (May 18th-21th, 2007)

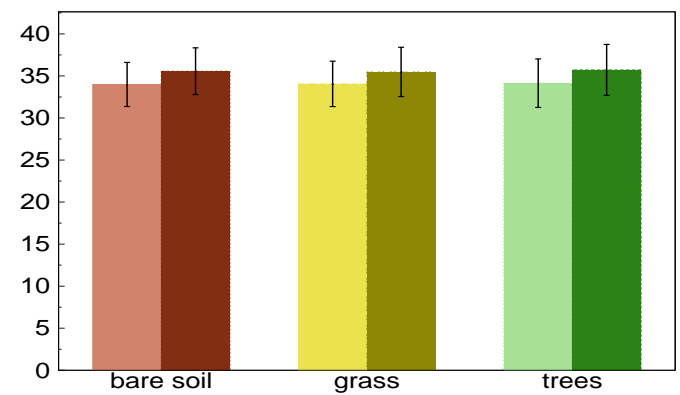

C $\quad$ CP7 (May 22th-25th, 2007)

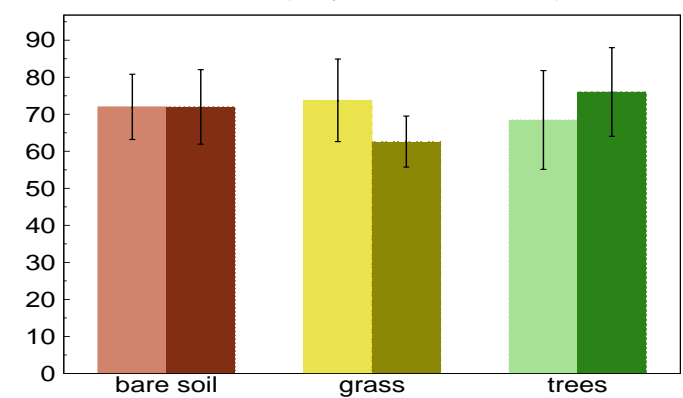

Figure S11. Area-averaged accumulated precipitation for the three convective precipitation [mm] experiments CP5, CP6 and CP7 characterized by higher synoptic forcing (higher synoptic wind speed, frontal lifting). The light bars represent the low initial soil moisture, the darker bars the high soil moisture case. 
a)

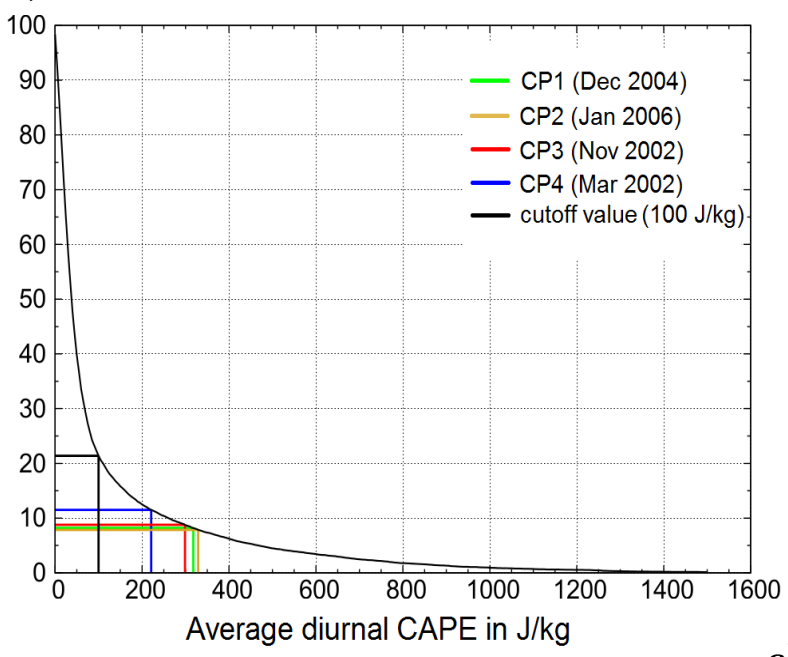

b)

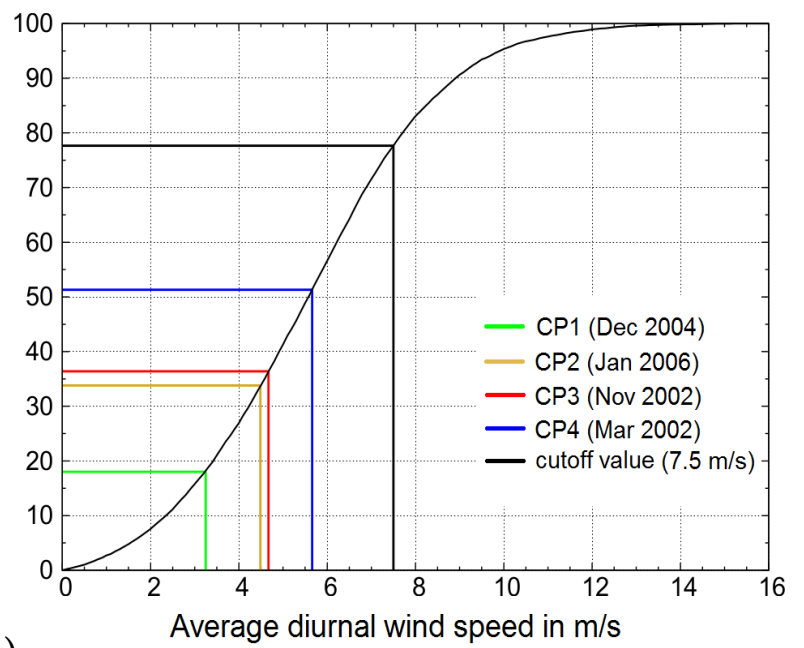

c)

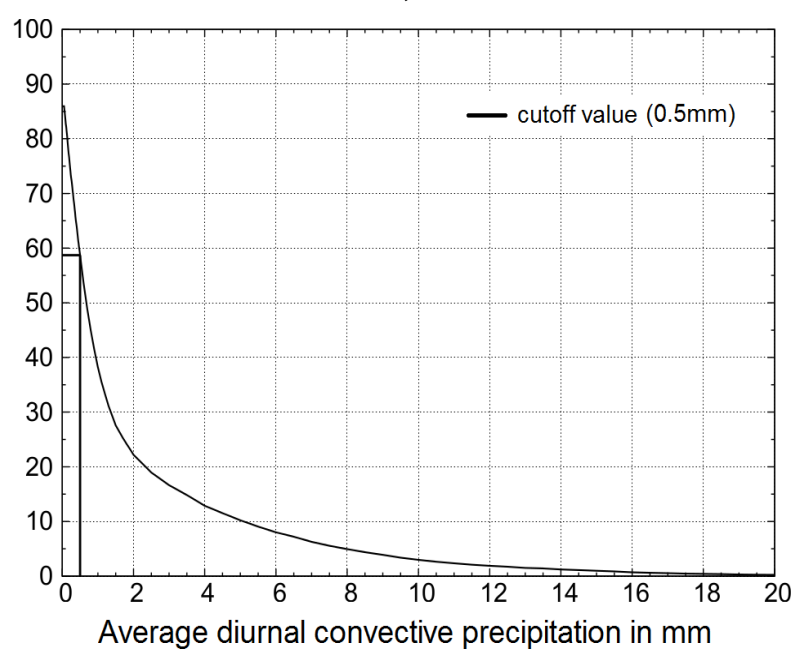

Figure S12. Analysis of ERA-Interim time series for Easter Island region from 01-01-1979 to 12-31-2014 (13149 days) : a) Relative frequency [\%] of days with diurnal mean CAPE above certain value. b) Relative frequency [\%] of days with diurnal mean wind speed below certain value. c) Relative frequency [\%] of days with diurnal convective precipitation sum above certain value. The coloured bars denote the pair of values for each of the four convective case studies CP1-CP4. The black bars denote the chosen cut-off values used for the upper-limit estimation of occurrence of synoptically undisturbed convective weather situations. 


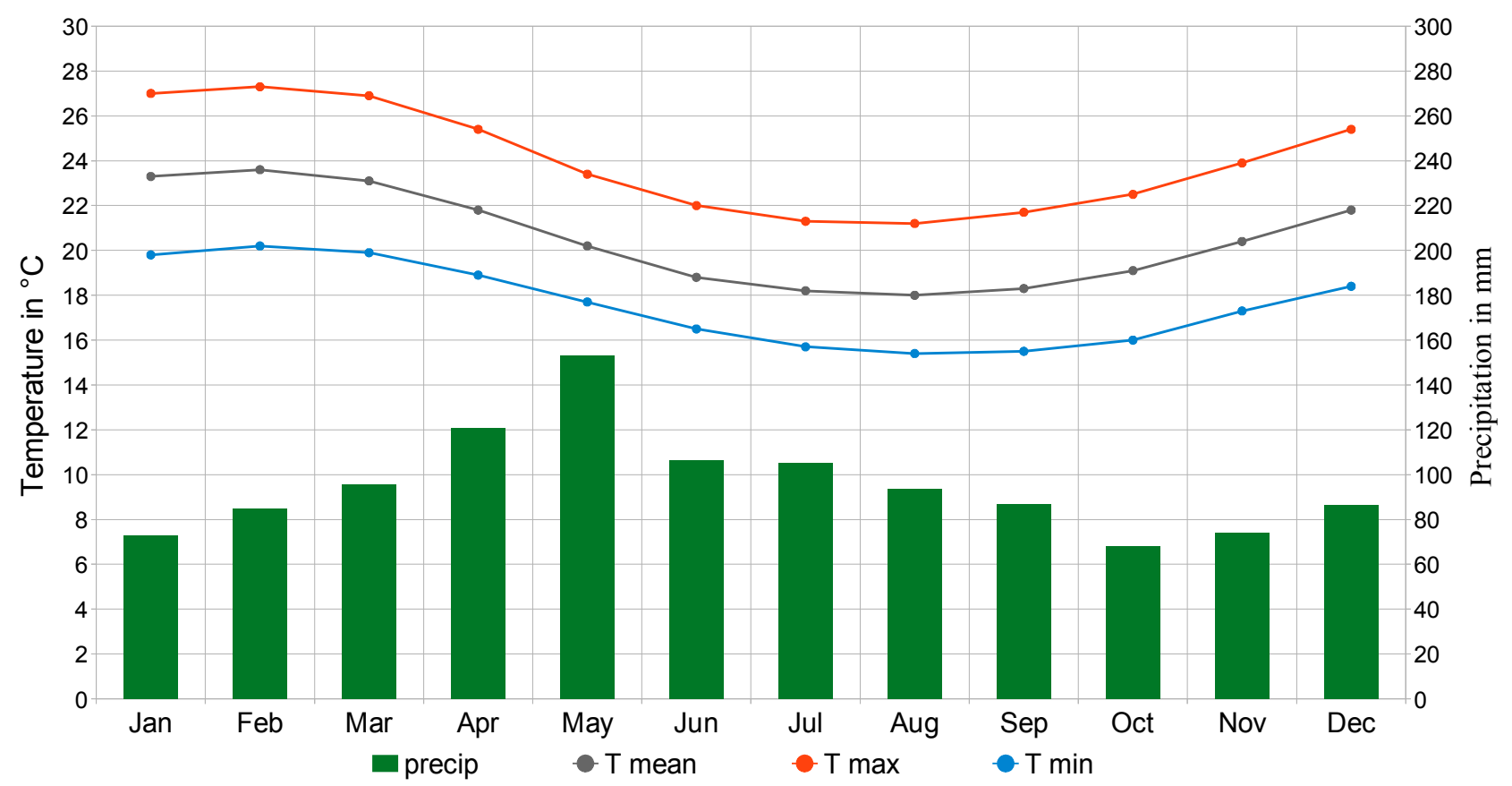

Figure S13. Average daily mean temperature and precipitation sum per month from 1961-1990 normals (based on World Meteorological Organization, 2010) and average daily maxima and minima temperatures (based on Universidad de Chile, 2011) 
Table S1. Setting of external (constant) land surface and vegetation parameters for the three land surface setups

\begin{tabular}{|c|c|c|c|c|c|c|}
\hline & PLCOV & LAI & $\mathrm{ALB}_{\mathrm{DRY}}$ & $\mathrm{ALB}_{\mathrm{VEG}}$ & $\mathrm{z}_{0}$ & $\mathrm{~d}_{R}$ \\
\hline $100 \%$ tree cover $(\mathrm{TC})$ & 1 & 6 & 0.14 & 0.13 & 1.07 & 0.7 \\
\hline $70 \%$ grass cover $(\mathrm{GC})$ & 0.7 & 1 & 0.14 & 0.2 & 0.03 & 0.12 \\
\hline bare soil (BS) & 0 & 0 & 0.14 & - & 0.005 & - \\
\hline
\end{tabular}

PLCOV: plant cover fraction LAI: leaf area index $\quad \mathrm{ALB}_{\mathrm{DRY}}$ : albedo of dry soil $\mathrm{ALB}_{\mathrm{VEG}}$ : albedo of vegetated area $\mathrm{z}_{0}$ : roughness length in $\mathrm{m} \mathrm{d}_{R}$ : root depth in $\mathrm{m}$ 
Table S2. Brief description of all 14 case studies. CSC stands for clear sky case studies, LSP for large scale precipitation and CP for convective precipitation. Every case study begins at 0600 UTC (0000 LT) and ends at the same time of day.

\begin{tabular}{|c|c|}
\hline $\begin{array}{c}\text { CSC1 } \\
\text { Jan 2011, 21-25 }\end{array}$ & $\begin{array}{l}\text { mostly clear sky with high insolation and some low cumulus clouds at daytime; easterly winds on all } \\
\text { four days with a medium wind speed of about } 6 \mathrm{~m} / \mathrm{s} \text {; mean sea surface temperature (SST) of } 24.5^{\circ} \mathrm{C}\end{array}$ \\
\hline $\begin{array}{c}\text { CSC2 } \\
\text { Dec 2011, 01-06 }\end{array}$ & $\begin{array}{l}\text { mostly clear sky with high insolation and some low and medium clouds during daytime; wind from S } \\
\text { at the first day, then } 2 \text { days of easterly wind, then turning to northerly; mean wind speed of about } 4 \mathrm{~m} / \mathrm{s} \text {; } \\
\text { SST } 21.3^{\circ} \mathrm{C}\end{array}$ \\
\hline $\begin{array}{c}\text { CSC3 } \\
\text { Jul 2004, 09-13 }\end{array}$ & $\begin{array}{l}\text { mixed conditions with rather low insolation: first day sunny and then more and more clouds at medium } \\
\text { and high clouds; westerly wind on the first day, second day from all directions, last two days northerly; } \\
\text { mean wind speed between } 3 \mathrm{~m} / \mathrm{s} \text { on the second day and } 9 \mathrm{~m} / \mathrm{s} \text { at the fourth day; SST } 21.2^{\circ} \mathrm{C}\end{array}$ \\
\hline $\begin{array}{c}\text { LSP1 } \\
\text { Jul 2005, 25-28 }\end{array}$ & $\begin{array}{l}\text { wide rain band (most likely warm front of a approaching low pressure system) with moderate rain during } \\
\text { first and second day; relatively strong northwesterly wind with speeds up to } 13^{\circ} \mathrm{m} / \mathrm{s} \text {; SST } 20.7^{\circ} \mathrm{C}\end{array}$ \\
\hline $\begin{array}{c}\text { LSP2 } \\
\text { Sep 2009, 27-30 }\end{array}$ & $\begin{array}{l}\text { first two days no rain and moderate northerly winds; then arrival of occlusion front with widespread } \\
\text { heavy rain and a sudden wind change to S; SST } 20.9^{\circ} \mathrm{C}\end{array}$ \\
\hline $\begin{array}{c}\text { LSP3 } \\
\text { Jul 2003, 26-29 }\end{array}$ & $\begin{array}{l}\text { Strong } 36 \text {-hour lasting rainfall from day } 2 \text { on due to a slow moving front; first day } \mathrm{N} \text { wind with } 8 \mathrm{~m} / \mathrm{s} \text { to } \\
11 \mathrm{~m} / \mathrm{s} \text {, then wind jump to S/SE with similar speeds; SST } 21.3^{\circ} \mathrm{C}\end{array}$ \\
\hline $\begin{array}{c}\text { LSP4 } \\
\text { Nov 2009, 02-05 }\end{array}$ & $\begin{array}{l}\text { Slow moving warm front causing moderate widespread rain on all three days; wind from N/NE for the } \\
\text { entire time with speeds between } 9 \mathrm{~m} / \mathrm{s} \text { and } 14 \mathrm{~m} / \mathrm{s} \text {; SST } 20.7^{\circ} \mathrm{C}\end{array}$ \\
\hline $\begin{array}{c}\text { CP1 } \\
\text { Dec 2004, 22-26 }\end{array}$ & $\begin{array}{l}\text { calm conditions within the centre of a widespread high pressure system; nearly no synoptic wind on all } \\
\text { four days; CAPE rises throughout the four day period exceeding } 1000 \mathrm{~J} / \mathrm{kg} \text { on the last day; Lifted Index } \\
-4 \text { on last day representing moderate instability; SST } 21.2^{\circ} \mathrm{C}\end{array}$ \\
\hline $\begin{array}{c}\text { CP2 } \\
\text { Jan 2006, 05-09 }\end{array}$ & $\begin{array}{l}\text { large-scale synoptic situation similar to } \mathrm{CP} 1 \text { with unstable stratification on all four days characterized } \\
\text { by CAPE }>1000 \mathrm{~J} / \mathrm{kg} \text { and Lifted Index of }-4 \text { at times; SST } 21.2^{\circ} \mathrm{C}\end{array}$ \\
\hline $\begin{array}{l}\text { CP3 } \\
\text { Nov 2002, 16-20 }\end{array}$ & $\begin{array}{l}\text { small trough induces small area of strong synoptic lifting in the first two days (Easter Island not directly } \\
\text { affected); on the last day increasing instability and low wind speed of around } 4 \mathrm{~m} / \mathrm{s} \text {; SST } 20.7^{\circ} \mathrm{C}\end{array}$ \\
\hline $\begin{array}{c}\text { CP4 } \\
\text { Mar 2002, 21-25 }\end{array}$ & $\begin{array}{l}\text { rather calm conditions with moderate instability throughout all } 4 \text { days; synoptic wind form E/SE, } \\
\text { stronger on day } 1 \text { and } 4(9 \mathrm{~m} / \mathrm{s}) \text { and weak on day } 2 \text { and } 3(3-4 \mathrm{~m} / \mathrm{s}) ; \text { SST } 21.2^{\circ} \mathrm{C}\end{array}$ \\
\hline $\begin{array}{l}\text { CP5 } \\
\text { Feb 2004, 17-20 }\end{array}$ & $\begin{array}{l}\text { warm air advection from } \mathrm{N} \text { between a high pressure system in the east and a low pressure system in the } \\
\text { southwest; CAPE high at the first day }(1000 \mathrm{~J} / \mathrm{kg}) \text {, then declining slowly; steady wind between } 6 \mathrm{~m} / \mathrm{s} \text { and } \\
10 \mathrm{~m} / \mathrm{s} \text { from N; SST } 26.0^{\circ} \mathrm{C}\end{array}$ \\
\hline $\begin{array}{l}\text { CP6 } \\
\text { May 2007, 18-21 }\end{array}$ & $\begin{array}{l}\text { In front of a small trough with some synoptic scale lifting; very high CAPE values }(800 \mathrm{~J} / \mathrm{kg}-1500 \mathrm{~J} / \mathrm{kg} \\
\text { most of the time) and steady N wind between } 8 \mathrm{~m} / \mathrm{s} \text { and } 13 \mathrm{~m} / \mathrm{s} \text {; several lines of organized convection; } \\
\text { SST } 21.3^{\circ} \mathrm{C}\end{array}$ \\
\hline $\begin{array}{l}\text { CP7 } \\
\text { May 2007, 22-25 }\end{array}$ & $\begin{array}{l}\text { As in CP6, organized convection forms at the end of the case study; CAPE lower than in CP6 (around } \\
500 \mathrm{~J} / \mathrm{kg} \text { most of the time); steady } \mathrm{N} \text { wind with a speed between } 5 \mathrm{~m} / \mathrm{s} \text { and } 9 \mathrm{~m} / \mathrm{s} \text {; SST } 21.2^{\circ} \mathrm{C}\end{array}$ \\
\hline
\end{tabular}


Table S3. Area-averaged variables for all experiments of clear sky case study CSC1 (January 2011). White background: averaged in time over whole experiment (4 days). Yellow background: 4-day midday mean (11am-3pm local time), Red (Blue) : Temporal maximum (minimum)

\begin{tabular}{|c|c|c|c|c|c|c|c|c|c|}
\hline & \multicolumn{3}{|c|}{$80 \%$ soil moisture } & \multicolumn{3}{|c|}{$50 \%$ soil moisture } & \multicolumn{3}{|c|}{$10 \%$ soil moisture } \\
\hline & bare & grass & trees & bare & grass & trees & bare & grass & trees \\
\hline$S W \downarrow$ & 921.8 & 872.8 & 891.8 & 918.3 & 870.0 & 885.6 & 899.3 & 864.2 & 853.1 \\
\hline$L W \uparrow$ & 146.8 & 123.0 & 96.8 & 188.8 & 147.9 & 103.7 & 193.8 & 162.1 & 113.1 \\
\hline$H \uparrow$ & 291.5 & 248.9 & 136.9 & 508.1 & 454.9 & 324.8 & 535.1 & 575.6 & 694.6 \\
\hline$L E \uparrow$ & 318.1 & 393.0 & 611.7 & 17.0 & 136.4 & 406.0 & 0.0 & 0.0 & 0.0 \\
\hline$G \downarrow$ & 147.3 & 95.9 & 36.7 & 187.9 & 119.5 & 43.6 & 160.3 & 114.5 & 49.0 \\
\hline$B$ & 1.23 & 0.70 & 0.22 & 30.53 & 3.33 & 0.80 & - & - & - \\
\hline$T_{2 \mathrm{~m}}$ & 22.6 & 22.2 & 21.4 & 23.6 & 23.2 & 22.4 & 23.7 & 23.5 & 23.4 \\
\hline$T_{2 \mathrm{~m}}$ & 26.5 & 25.9 & 24.7 & 27.5 & 26.9 & 26.0 & 27.6 & 27.6 & 27.8 \\
\hline$T_{2 \mathrm{~m}}$ & 19.4 & 19.3 & 18.8 & 19.7 & 19.6 & 19.3 & 19.9 & 19.7 & 19.5 \\
\hline$T_{\mathrm{S}}$ & 24.7 & 22.8 & 21.1 & 29.1 & 25.9 & 22.5 & 29.6 & 27.2 & 24.1 \\
\hline$T_{\mathrm{S}}$ & 40.1 & 32.9 & 25.5 & 46.4 & 37.0 & 27.6 & 47.2 & 39.8 & 30.7 \\
\hline$T_{\mathrm{S}}$ & 16.6 & 16.8 & 17.4 & 17.9 & 17.7 & 18.2 & 18.4 & 18.1 & 18.6 \\
\hline$R H_{2 \mathrm{~m}}$ & 66.2 & 68.1 & 74.1 & 58.6 & 60.8 & 65.9 & 57.5 & 58.2 & 58.6 \\
\hline$R H_{2 \mathrm{~m}}$ & 82.9 & 83.8 & 88.1 & 82.1 & 81.9 & 82.6 & 78.9 & 79.2 & 79.3 \\
\hline$R H_{2 \mathrm{~m}}$ & 47.0 & 50.2 & 60.3 & 41.8 & 44.9 & 50.6 & 41.0 & 41.2 & 40.5 \\
\hline$v_{10 \mathrm{~m}}$ & 5.87 & 5.15 & 2.83 & 6.35 & 5.58 & 3.07 & 6.40 & 5.75 & 3.49 \\
\hline$C C_{\text {tot }}$ & 18.5 & 18.5 & 17.5 & 19.7 & 19.6 & 18.7 & 19.9 & 19.8 & 21.9 \\
\hline$E_{\mathrm{acc}}$ & 21.12 & 24.56 & 36.23 & 2.34 & 8.19 & 23.11 & 0.00 & 0.00 & 0.00 \\
\hline
\end{tabular}

$S W \downarrow:$ net short-wave radiation $\downarrow\left[\mathrm{W} / \mathrm{m}^{2}\right] \quad L W \uparrow:$ net long-wave radiation $\uparrow\left[\mathrm{W} / \mathrm{m}^{2}\right]$

$H \uparrow:$ sensible heat flux $\uparrow\left[\mathrm{W} / \mathrm{m}^{2}\right] \quad L E \uparrow:$ latent heat flux $\uparrow\left[\mathrm{W} / \mathrm{m}^{2}\right]$

$G \downarrow$ : ground heat flux $\downarrow\left[\mathrm{W} / \mathrm{m}^{2}\right] \quad T_{2 \mathrm{~m}, \mathrm{~S}}: 2 \mathrm{~m}$ air/surface temperature $\left[{ }^{\circ} \mathrm{C}\right]$

$R H_{2 \mathrm{~m}}: 2 \mathrm{~m}$ relative humidity [\%] $\quad v_{10 \mathrm{~m}}: 10 \mathrm{~m}$ wind speed [m/s]

$C C_{\text {tot }}$ : total cloud cover $[\%] \quad E_{\text {acc }}$ : accumulated evaporation $[\mathrm{mm}] \quad B$ : Bowen ratio 
Table S4. Relative frequency of days [\%] and their contribution to total rain amount [\%] in Easter Island region for the chosen cutoff values and the combination of all three.

rel. frequency of days contribution to total precip

\begin{tabular}{lll} 
CAPE $>100 \mathrm{~J} / \mathrm{kg}$ & 21.39 & 53.56 \\
wind speed $<7.5 \mathrm{~m} / \mathrm{s}$ & 77.66 & 56.05 \\
conv. precip. $>0.5 \mathrm{~mm}$ & 58.70 & 94.33 \\
\hline all three combined & 13.70 & 27.60 \\
\hline
\end{tabular}


Table S5. Average time between two dry periods with a precipitation sum below a certain value and longest dry periods for Easter Island. left value: based on daily precipitation measurement at Mataveri Airport from 01-01-1979 to 12-31-2014, right value: based on daily ERAInterim precipitation data from 01-01-1979 to 12-31-2014

\begin{tabular}{ccccc}
\hline & \multicolumn{5}{c}{ Accumulated precipitation below } \\
Length of dry period [days] & $<2 \mathrm{~mm}$ & $<5 \mathrm{~mm}$ & $<10 \mathrm{~mm}$ & $<20 \mathrm{~mm}$ \\
\hline 7 & $1 / 1 \mathrm{mon}$ & $3 / 2 \mathrm{wk}$ & $2 / 2 \mathrm{wk}$ & $2 / 1.5 \mathrm{wk}$ \\
15 & $11 / 28 \mathrm{mon}$ & $4 / 3 \mathrm{mon}$ & $2 / 1 \mathrm{mon}$ & $1 / 1 \mathrm{mon}$ \\
30 & $17.5 /-\mathrm{yr}$ & $17.5 / 17.5 \mathrm{yr}$ & $28 / 16 \mathrm{mon}$ & $7 / 3 \mathrm{mon}$ \\
45 & $-/-$ & $-/-$ & $35 /-\mathrm{yr}$ & $84 / 17 \mathrm{mon}$ \\
60 & $-/-$ & $-/-$ & $-/-$ & $-/ 12 \mathrm{yr}$ \\
\hline \hline Longest dry period [days] & $32 / 19$ & $35 / 30$ & $48 / 38$ & $54 / 64$ \\
\hline
\end{tabular}

